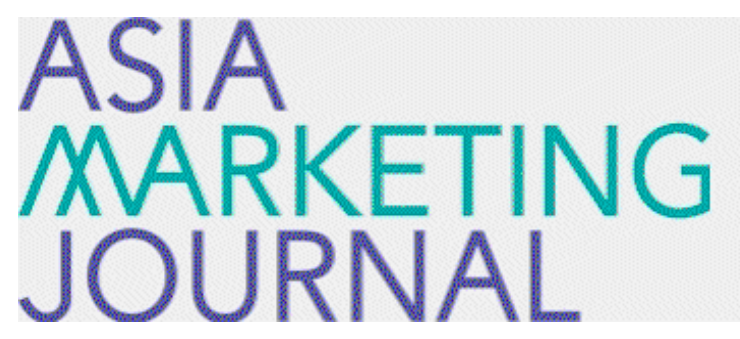

ASIA MARKETING JOURNAL

Volume 3 | Issue 3

Article 3

9-1-2001

\title{
기술적 대체를 반영한 확산모형에 대한 연구
}

Se Hoon Park

Follow this and additional works at: https://amj.kma.re.kr/journal

Part of the Marketing Commons

\section{Recommended Citation}

Park, Se Hoon (2001) "기술적 대체를 반영한 확산모형에 대한 연 구," Asia Marketing Journal: Vol. 3 : Iss. 3 , Article 3.

Available at: https://doi.org/10.53728/2765-6500.1069

This Article is brought to you for free and open access by Asia Marketing Journal. It has been accepted for inclusion in Asia Marketing Journal by an authorized editor of Asia Marketing Journal. 


\title{
기술적 대체를 반영한 확산모형에 대한 연구*
}

\section{A Study on Diffusion Models Capturing Technological Substitution}

\author{
박세훈(성균관대학교 경영학부 교수) \\ sehoon@yur im.skku. ac.kr
}

\begin{abstract}
본 연구는 첨단기술 제품들에서 볼 수 있는 지속적인 기술혁신으로 인하여 새롭게 시 장에 진입하는 신규세대 제품과 이전세대 제품들의 동태적 판매량을 묘사하고 예측할 수 있는 모형들을 제시하고 비교·분석하는데 목적이 있다.

본 논문에서는 Bass(1969)의 내구성 소비재에 대한 최초구매 확산모형을 기반으로 하여 개발된 기술적 대체를 반영한 확산모형들, 즉 Norton and Bass(1987), Mahajan and Muller(1996), Jun and Park(1999)의 모형들의 이론적인 틀과 가정들올 비교·분석함으로써 기 존 모형과는 변수와 계수의 의미가 다른 모형을 제시하고, 전세계 DRAM 반도체 출하량 자료를 사용하여 모형들 간의 경헙적 비교를 행하였다.

Jun and Park(1999)이 전세계 DRAM 반도체 출하량 자료에 적용하기 위하여 새롭게 개 발한 타입 II 모형(즉 JP2)은 본 연구의 경험적 비교의 결과에 비추어 볼 때 그들의 타입 I 모형이 취한 가정들을 변화시켜서 모형올 구성하는 변수들과 계수들의 의미가 달라진 JPI 모형 또는 Norton and Bass(1987)의 모형(즉 NBI)보다 실제 적용에 있어서 열등할 수 있다는 것을 본 연구는 보여주었다.
\end{abstract}

* 논문접수: 02.03 게재확정: 02.04 


\section{1. 서 론}

새로운 기술들(new technologies)은 계속적으로 이전의 기술들(earlier technologies)을 대체하 여 왔고, 특히 첨단기술 (high-technologies) 제품 영역에서는 그 대체의 속도가 빨라지는 것 을 볼 수 있다. 첨단기술 제품에서는 지속적인 기술혁신(technological innovation)으로 신규세 대(new generation)와 이전 세대들(earlier generation)간의 대체 시기가 점점 짧아짐에 따라서 신 규세대 제품의 수요와 신규세대 제품의 시장 도입이 이전세대 제품들의 수요에 미치는 영향 을 이해하는 것은 마케터에게 있어서 매우 중요한 작업이 되었다.

신규세대 제품은 이전세대 제품들이 충족시키지 못했던 소비자들의 욕구충족을 가능하게 하므로 새로운 수요 창출을 통하여 시장을 확대할 수도 있지만, 동시에 이전세대 제품의 (잠재) 구매자들에게 신규세대 제품으로 대체할 수 있는 기회를 제공한다. 이러한 세대간 대 체효과(substitution effects)는 궁극적으로 이전세대 제품의 수요를 다옴과 같은 두 가지 방향 에서 감소시킬 것이다. 첫째, 신규세대 제품이 시장에 존재하지 않는다면 이전세대 제품을 수용(adoption)하였을 소비자들이 이전세대 제품 대신에 신규세대 제품을 수용하는 경우와 둘째, 이미 이전세대 제품올 수용한 소비자들이 이전세대 제품으로부터 신규세대 제품으로 전환(switching)하는 경우를 들 수 있다.

그런데 신규세대 제품이 이전세대에 비해서 매우 우월할 지라도 모든 잠재 구매자들에게 즉각적으로 수용될 수 없고 확산과정(diffusion process)올 거치게 된다. 이전세대 제품 또한 신규세대 제품으로의 대체과정(substitution process)이 진행 중일지라도 잠재시장(potential market)에서 확산이 지속되어 이전세대 제품에 대한 수요가 상당 기간동안 성장하였다가 궁 극적으로 감소.소멸하는 것을 볼 수 있다. 본 연구는 첨단기술 제품들에서 볼 수 있는 지속 적인 기술 혁신으로 인하여 새롭게 시장에 진입하는 신규 세대 제품과 이전세대 제품들의 동태적 판매랑을 묘사하고, 신규세대와 이전세대 제품들의 수요를 예측할 수 있는 모형들을 제시하고 비교·분석하는데 목적이 있다.

본 논문에서는 첨단기술 제품들 중에서 DRAM(dynamic random access memory) 반도체와 같 은 내구성 기술제품(durable technology)에서 볼 수 있는 세대별 확산과정과 세대간 대체과정 을 동시에 반영할 수 있는 퉁합모형들(integrated models)을 비교.분석하고자 한다. 가령 DRAM 반도체의 대체 및 확산 과정을 살펴보면, 1970 년에 $1 \mathrm{k}$ 메모리칩이 시장에 도입된 이 후에 $4 \mathrm{k}, 16 \mathrm{k}, 64 \mathrm{k}, 256 \mathrm{k}, 1 \mathrm{M}, 4 \mathrm{M} \ldots$ 둥으로 신규세대와 이전세대들 간에 시간이 흐를수록 더 빠 른 기술적 대체와 세대별 확산 현상이 나타넜다. <그림1>은 $4 \mathrm{k}, 16 \mathrm{k}, 64 \mathrm{k}, 256 \mathrm{k}$ DRAM의 확산 과 대체 과정의 결과를 보여주는 1974년 1분기부터 1985년 2분기까지 분기별 전세계 DRAM 의 출하량(shipments)을 나타내고 있다.

DRAM 반도체와 같은 첨단기술 제품들에서 신규세대(new generation)는 이전세대들(earlier generations)에 비해서 보다 급격한 성장과 쇠퇴가 나타남으로써 수명주기(life cycle)가 점점 단축되는데 반해서, 새로운 세대일수록 잠재시장규모(market potential)는 신규세대에 대한 순 수한 쳐초구매자(pure first purchasers)뿐만 아니라 이전세대률 수용하였던 소비자들이 그 제품 의 사용올 포기하고 더 신규세대의 제품을 구매하는 업그래이더(upgraders)로 인해서 더 커 지는 것을 볼 수 있다. 이러한 기술적 대체와 확산 과정올 모형화하기 위해서 본 연구에서 는 Bass(1969)의 내구성 소비재(consumer durable goods)에 대한 최초구매 확산모형(first purchase diffusion model)을 기반으로 하여 개발된 기술적 대체를 반영한 확산모형들(가령 
Norton and Bass 1987 ; Mahajan and Muller 1996 ; Jun and Park 1999)을 모형의 이론적인 튤과 가 정들을 비교.분석함으로써 기존 모형과는 변수와 계수의 의미가 다른 모형을 제시하고, <그 림 1>에서 보여준 전세계 DRAM 반도체 출하량 자료를 사용하여 모형들 간의 경헙적 비교 를 행하고자 한다.

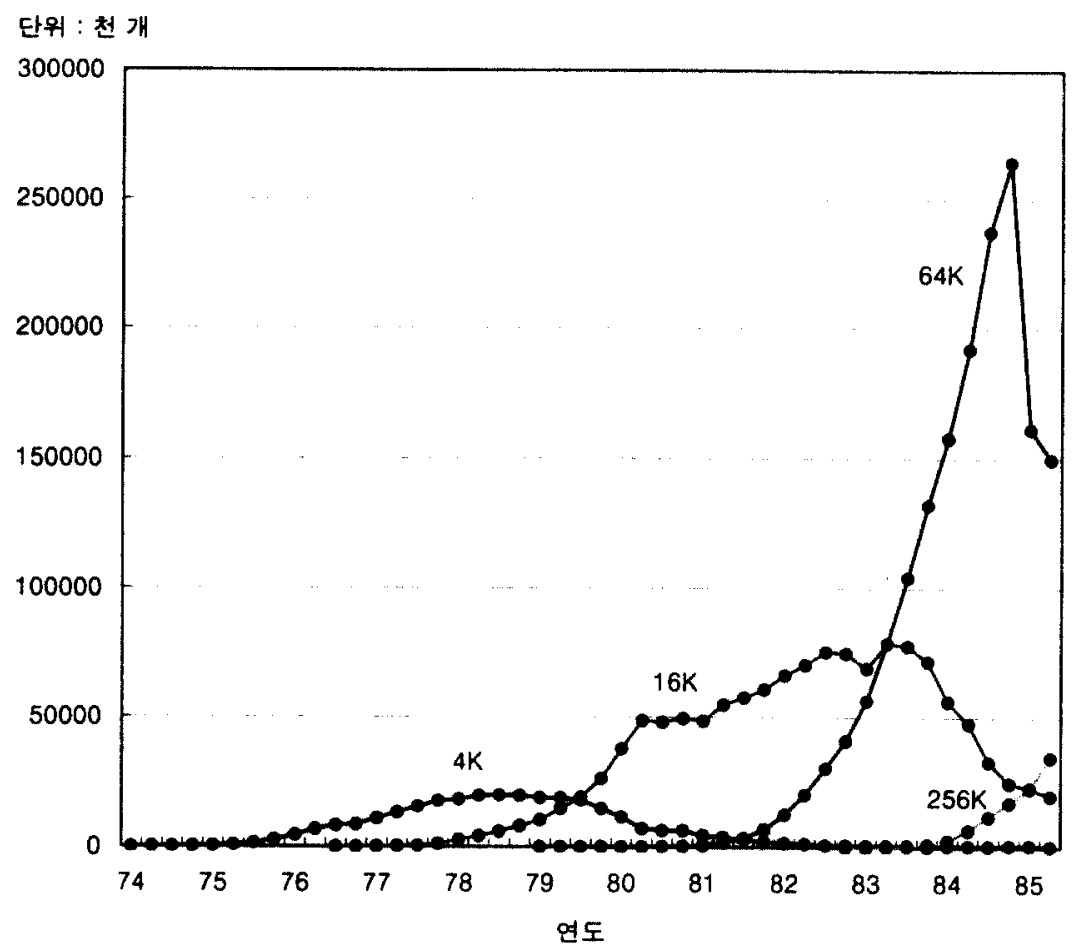

\section{2. 내구성 기술제품에 대한 확산모형}

\section{1. 단일 세대 내구재의 확산모형}

신제품의 수요 성장을 묘사하고 예측하기 위하여 많은 확산모형들이 개발되어왔다 (Mahajan, Muller, and Bass 1990). 개발된 모형들의 대부분은 단일 신제품(a single new product)을 대상으로 하였고 그 신제품이 기존 제품들과는 독립적인(즉 관계가 없는) 것으로 가정하였 다. 이러한 확산모형들 중에서 가장 대표적인 모형으로 Bass(1969)의 최초구매 확산모형 (first-purchase diffusion model)을 들 수 있다. Bass의 기본 모형은 TV, 에어컨과 같은 내구성 소비재(consumer durable good)를 대상으로 하고 있으므로 짧은 기간동안에 소비자의 반복구 매(repeat purchase)는 없고, 구매자는 단지 한 단위(one unit)만을 구입하는 것으로 가정하였다. 따라서 신제품 수용자들(adopter)의 수는 신제품의 판매량(unit sales)과 같은 것으로 정의할 수 있다. 
Bass 모형은 신제품의 잠재 수용자들(potential adopters)은 대중매체 커뮤니케이션(mass media communication)과 구전 커뮤니케이션(word-of-mouth communication)의 두 가지 커뮤니케 이션 수단에 의해서 영향을 받고 신제품을 수용하게 된다고 가정한다. 즉 신제품 수용자들 은 대중매체 커뮤니케이션에 의한 영향(즉 외부영향(external influence))을 받고 신제품올 수 용한 집단과 구전 커뮤니케이션에 의한 영향(즉 내부영향(internal influence))을 받아서 신제품 을 수용한 집단으로 양분되는데, Bass는 첫번째 집단과 두번째 집단울 각각 혁신자 (innovators) 집단과 모방자(imitators)집단으로 명명하였다. 그러므로 Bass모형은 혁신의 확산 (diffusion of innovation)과 수용에 대한 사회학 연구들(가령 Rogers 1983)과 일맥상통한 행동적 근거(behavioral rationale)를 갖고 있으며, 아직까지 신제품을 수용하지 않은 잠재구매자가 $\mathrm{t}$ 시점에야 비로소 신제품을 수용할 조건부 확률(conditional probability), 즉 해저드 함수(hazard function)는 다음과 같은 기본적인 전제(fundamental premise)로 표현된다.

$$
f(t) /[1-F(t)]=p+q F(t)
$$

여기서 $f(t)$ 는 $\mathrm{t}$ 시점에서 수용(adoption)이 발생할 확률 또는 $\mathrm{t}$ 시점에 신제품을 수용하 는 궁극적 잠재시장의 일부분(fraction)이고, $F(t)$ 는 $\mathrm{t}$ 시점 바로 이전까지 신제품을 수용한 궁극적인 잠재시장의 부분(fraction)을 나타내고, 해저드 함수를 표현한 식(2.1)의 오른쪽에서 $p$ 와 $q$ 는 각각 외부영향을 나타내는 혁신계수(coefficient of innovation)와 내부영향올 나타내 는 모방계수(coefficient of imitation) 이다.

식(2.1)은 다음과 같은 미분 방정식(differential equation)으로 나타낼 수 있다.

$$
f(t) \equiv \frac{d F}{d t}=[p+q F(t)][1-F(t)]=p+(q-p) F(t)-q[F(t)]^{2}
$$

만약 $F(0)=0$ 이라면 미분 방정식 (2.2)의 해는 다음과 같다.

$$
F(t)=[1-\exp (-(p+q) t)] /[1+(q / p) \exp (-(p+q) t)]
$$

긍극적 수용자들(ultimate adopters)의 총수, 즉 잠재시장의 크기(market potential)를 $M$ 으로 나타내고 각 수용자는 단지 한 단위(only one unit) 만을 구매한다면, $t$ 시점의 판매율(sales rate) $S(t)$ 와 $\mathrm{t}$ 시점까지의 누적판매량(cumulative sales) $Y(t)$ 는 각각 다음과 같이 표현된다.

$$
\begin{aligned}
& S(t)=M f(t) \\
& Y(t)=M F(t)
\end{aligned}
$$

여기서 $F(t)$ 는 식(2.3)과 같고 $f(t)$ 는 $F(t)$ 률 시간 $\mathrm{t}$ 에 대해서 미분한 것이다. 식 (2.2)의 양변에 잠재시장의 크기 $\mathrm{M}$ 을 곱하고 식(2.4)와 식(2.5)와 같이 표현된 $S(t)$ 와 $Y(t)$ 를 사용 하여 변화된 식(2.2)를 나타내면 다음과 같다. 


$$
\begin{aligned}
S(t) & =[p+(q / M) Y(t)][M-Y(t)] \\
& =p M+(q-p) Y(t)-(q / M)[Y(t)]^{2}
\end{aligned}
$$

Bass의 기본모형은 식(2.4) 또는 식(2.6)과 같이 나타낼 수 있는데, 식(2.4)는 시간 영역(time domain)에서 그리고 식(2.6)온 누적수용 영역(cumulative adoption domain)에서 Bass 모형을 표 현한 것이다(Bass, Krishnan and Jain 1994). Bass 모형을 이용하여 신제품의 확산과정을 예측하 기 위해서는 과거의 판매량 자료(prior sales data)를 사용하여 Bass 모형에서의 세 개의 모수 들(parameters)인 $p, q, M$ 을 측정하여야 한다. 그러나 실제의 판매량 자료는 연속적 시간 (continuous time)으로 나타나지 않고 이산적 시간(discrete time)으로, 가령 연도별, 분기별 둥으 로 나타나 있으므로 식(2.4) 또는 식(2.6)을 이산적 형태(discrete analog)의 희귀모형 (regression model)으로 표현하여야 한다. 이제부터는 t를 연속적 시간인 $\mathrm{t}$ 시점 대신에 이산적 시간인 $\mathrm{t}$ 期를 나타내는 것으로 본다.

Bass(1969)는 식(2.6)의 이산적 형태로서 다음과 같은 회귀모형을 도출하고 그 모형의 모수 들인 $p, q, M$ 을 추정하기 위한 OLS(ordinary least squares) 추정절차률 제안하였다.

$$
\begin{aligned}
S(t) & =[p+(q / M) Y(t-1)][M-Y(t-1)] \\
& =p M+(q-p) Y(t-1)-(q / M)[Y(t-1)]^{2}
\end{aligned}
$$

여기서 $S(t)$ 는 $\mathrm{t}$ 期의 판매량이고, $Y(t-1)$ 은 (t-1) 期까지의 누적 판매량이다. 그러나 OLS 추정절차를 사용하면 식(2.7)에서 독립변수둘인 $Y(t-1)$ 과 $[Y(t-1)]^{2}$ 간에 다중공선성 (multicollinearity)이 발생할 가능성이 높으므로 모수추정치들온 불안정(unstable)하고 잘못된 부호를 가질 수 있다. 이러한 OLS 추정절차의 문제점율 극복하기 위하여 Schmittlein and Mahajan(1982)은 MLE(maximum likelihood estimation) 추정절차를 제안하였다. 하지만 MLE 추 정절차는 단지 표본추출 오차들(sampling errors)만을 고려하고, 확산과정에 영향을 미칠 수 있지만 모형에서 배제된 마케팅 변수들의 효과와 같은 오차들은 무시되었다고 Srinivsan and Mason(1986)은 지적하였다. 그래서 이러한 MLE 추정절차의 단점을 해결하기 위하여 Srinivasan and Mason(1986)은 식(2.4)를 이산적 형태의 판매량 자료에 적용할 수 있도록 다음 과 같은 회귀모형을 제시하고 모형의 모수들(즉 $p, q, M$ )을 직접적으로 추정하기 위한 NLS(nonlinear least squares) 추정절차를 제안하였다.

$$
S(t)=M(F(t)-F(t-1))
$$

여기서 $F(\bullet)=[1-\exp (-(p+q) \cdot \bullet)] /[1+(q / p) \cdot \exp (-(p+q) \cdot \bullet)]$ 이다. Mahajan, Mason, and Srinivasan(1986)은 경험적 비교(empirical comparison)를 통하여 OLS, MLE와 NLS 추정절차 중에서 NLS 추정절차의 전반적 우월성을 제시하였다.

\section{2. 다세대 제품들의 세대간 대체를 반영한 확산모형}

앞 절에서는 본 연구의 주제인 기술적 대체를 반영한 확산모형들이 기반으로 하는 단일 
세대(single generation)에 적용할 수 있는 Bass의 최초구매 확산모형과 추정절차를 살펴보았다. 본 절에서는 다세대(multigeneration) 기술제품에서 볼 수 있는 대체과정과 확산과정을 동시에 모형화한 기존 연구들을 이론적인 블과 가정에서 비교.분석함으로써 기존 모형의 변화된 형 태를 제시하고자 한다.

\subsubsection{Norton and Bass(1987)의 연구}

Norton and Bass(1987)는 <그림 1>에서 보여준 DRAM 반도체와 같온 산업재(industrial good) 의 세대간 대체과정과 확산과정을 동시에 포함하는 모형을 개발하였다. 그들은 DRAM 반 도체는 PC와 같은 웅용기기(applications)의 부품(device)으로 사용되는 산업용 내구재로서 최 종 사용자(end user)가 신제품올 수용하는 것으로 보기보다는 PC와 같은 웅용기기(제조희사) 들을 신제품 수용자(adopters)로 간주하였다. 신제품 수용자인 응용기기(제조희사)들은 기간당 (per time period) 한 단위(one unit)보다는 여러 단위(multiple units)의 DRAM 반도체를 구매할 것이고, 더 새로운 세대의 $\mathrm{DRAM}$ 반도체로 전환하기 前에는 여러 기간에 걸쳐서 기존에 수 용한 DRAM 반도체를 반복구매하게 된다. 어떤 특정 세대, 가령 i-세대의 DRAM 반도체가 시장에 도입되면 이전세대의 DRAM 반도체로는 생각하지 못했던 i-세대 DRAM 반도체의 용도들(uses)이 새로이 나타나고 이를 채용한 웅용기기들(applications)의 수는 시간이 흐름에 따라서 중가하지만 그 상한(upper limit)은 상수(constant)인 $M_{i}$ 로서 존재한다고 가정한다. 또 한 i-세대 DRAM 반도체를 수용한 웅용기기들의 i-세대 DRAM 반도체에 대한 평균 기간당 소비율(average per-period consumption)은 $r_{i}$ 로서 일정하다고 가정한다. 마지막으로 일단 어떤 웅용기기가 어떤 특정세대의 DRAM 반도체를 수용하게 되면 그 이전세대의 DRAM 반도체 로 돌아가지 않고 더 신규세대의 DRAM 반도체로 업그레이드만이 발생할 수 있다고 가정한 다.

위에서 언급한 이론적 틀과 가정에 기초하여 단일 세대(single generation) DRAM 반도체 판 매량의 확산모형을 표현하면 다음과 같다.

$$
S(t)=m F(t)
$$

여기서 $S(t)$ 는 단일 세대 $\mathrm{DRAM}$ 반도체의 $\mathrm{t}$ 期 판매량이고, $m=M \cdot r$ 로서 $m$ 은 단일 세대 DRAM 반도체의 잠재시장의 크기(market potential)를 나타내는데 이는 궁극적인 수용자 들, 즉 웅용기기들의 총수 $(M)$ 와 웅용기기들의 평균 기간당 소비율 $(r)$ 의 곱으로 표현된다. 식(2.9)로 표현된 Norton and Bass의 단일세대 내구재, 즉 DRAM 반도체의 확산모형은 앞 절 에서 살펴본 Bass(1969)의 최초구매 확산모형인 식(2.4)(또는 식(2.8))과는 다른 형태를 보이 고 있다. 그 이유는 식(2.9)에서는 DARM 반도체의 수용자(adopters)는 최종 사용자(end user) 가 아닌 웅용기기들(applications)로서 그들은 기간당 한 단위(one unit)만을 구매하지 않고 여 러 단위들(multiple units)을 구매하고, 또한 최초구매(first purchase)로서 끝나지 않고 일단 수 용하게 되면 계속적인 반복구매(repeat purchase)를 행하기 때문이다.

그러면 다음으로 다세대(multigeneration) DRAM 반도체들간의 대체과정과 확산과정에 대한 Norton and Bass의 모형을 설명하기 위해서, 편의상 $i=1,2,3,4$ 가 각각 $4 \mathrm{k}(1$ 세대), $16 \mathrm{k}$ (2세대), $64 \mathrm{k}$ (3세대), 256k(4세대) DRAM을 나타내는 것으로 놓는다. 먼저 1세대(4k)와 2세대(16k)만이 존재할 수 있는 DRAM 반도체 시장을 가정하여 Norton and Bass의 모형을 나타내면, 각 세대 
의 DRAM 출하량(판매량)온 다음과 같은 수식으로 표현할 수 있다.

$$
\begin{aligned}
& S_{1}(t)=F_{1}(t) m_{1}-F_{2}\left(t-\tau_{2}+1\right) F_{1}(t) m_{1} \\
& =F_{1}(t) m_{1}\left[1-F_{2}\left(t-\tau_{2}+1\right)\right] \\
& S_{2}(t)=F_{2}\left(t-\tau_{2}+1\right)\left[m_{2}+F_{1}(t) m_{1}\right]
\end{aligned}
$$

여기서 $S_{i}(t)$ 는 $\mathrm{i}$-세대 DRAM 반도체의 $\mathrm{t}$ 期 판매량이고, $m_{1}$ 은 1 세대 DRAM 반도체의 잠 재시장 크기(market potential)이고 $m_{2}$ 는 2세대 DRAM 반도체에 의해서 새롭게 창출.추가된 잠재시장 크기(incremental market potential)를 나타내며,

$F_{i}(\bullet)=\left[1-\exp \left(-\left(p_{i}+q_{i}\right) \cdot \bullet\right)\right] /\left[1+\left(q_{i} / p_{i}\right) \cdot \exp \left(-\left(p_{i}+q_{i}\right) \cdot \bullet\right)\right]$ 이다. 또한 $\tau_{2}$ 는 2 세대 $\mathrm{DRAM}$ 이 반도체 시장에 도입된 시기이며, $t<\tau_{2}$ 에 대해서 $F_{2}\left(t-\tau_{2}+1\right)=0$ 이다.

식(2.10)과 식(2.11)로 구성된 연립방정식 모형(simultaneous equation model)은 1세대와2세대 DRAM 반도체의 확산과 대체과정을 모두 포착하고 있다. 2 세대의 판매량, 즉 $S_{2}(t)$ 는 2 세 대 시장도입 시기(즉 $\tau_{2}$ ) 이후에 단조중가하지만, 1 세대 판매량, 즉 $S_{1}(t)$ 의 정점(peak)은 $\tau_{2}$ 시기 또는 그 이후에 발생한다. 1 세대는 2 세대의 시장도입 이후에 확산과 대체 과정을 거 치면서 어느 정도 성장할 수도 있지만 궁극적으로는 2 세대로의 대체과정을 거치면서 소멸하 고, 2세대의 궁극적 판매량 수준(ultimate sales level)은 1세대와 2세대 잠재시장 크기의 합이 될 것이다.

Norton and Bass의 모형을 1세대, 2세대, 3세대가 존재하는 시장에 적용해 보면, 1 세대는 더 신규세대들로의 전환을 통하여 2 세대와 3 세대 모두에게 1 세대의 실제 수용자들(actual adopters)과 잠재 수용자들(potential adopters)로부터의 판매량을 뻬앗길 수 있지만 2 세대는 이 전세대인 1 세대로부터 전환되어 들어오므로 1세대의 실제와 잠재 수용자들로부터의 판매량 을 빼앗아 올 수 있는 대신에 더 신규세대인 3세대로의 전환이 발생하므로 배앗아 온 1세대 의 실제와 잠재 수용자들을 포함하여 2 세대 나름의 실제와 잠재 수용자들을 뻬앗기는 3 세대 간 대체과정이 발생한다. 이러한 세대간 대체과정이 발생하는 동시에 각 세대별로는 세대 나름의 잠재시장으로부터의 확산과정 또한 발생한다.

<그림 1>에서 보여준 4k(1세대), $16 \mathrm{k}$ (2세대), 64k(3세대), 256k(4세대)가 존재하는 1974년 1분 기부터 1985년 2분기까지의 전세계 DRAM 반도체 시장에 적용할 수 있는 Norton and Bass의 모형을 수식으로 표현하면 다음과 같다.

$$
\begin{aligned}
& S_{1}(t)=F_{1}(t) m_{1}\left[1-F_{2}\left(t-\tau_{2}+1\right)\right] \\
& S_{2}(t)=F_{2}\left(t-\tau_{2}+1\right)\left[m_{2}+F_{1}(t) m_{1}\right]\left[1-F_{3}\left(t-\tau_{3}+1\right)\right] \\
& S_{3}(t)=F_{3}\left(t-\tau_{3}+1\right)\left[m_{3}+F_{2}\left(t-\tau_{2}+1\right)\left[m_{2}+F_{1}(t) m_{1}\right]\right]\left[1-F_{4}\left(t-\tau_{4}+1\right)\right] \\
& S_{4}(t)=F_{4}\left(t-\tau_{4}+1\right)\left[m_{4}+F_{3}\left(t-\tau_{3}+1\right)\left[m_{3}+F_{2}\left(t-\tau_{2}+1\right)\left[m_{2}+F_{1}(t) m_{1}\right]\right]\right]
\end{aligned}
$$


여기서 $S_{i}(t)=\mathrm{i}-$ 세대 DRAM 반도체의 $\mathrm{t}$ 期 판매량, $m_{i}=$ 이전세대들에 의해서는 충족될 수 없고 $\mathrm{i}$-세대 DRAM에 의해서 비로소 충족될 수 있는 새롭게 창출.추가된 잠재시장의 크 기, $F_{i}(\bullet)=\left[1-\exp \left(-\left(p_{i}+q_{i}\right) \cdot \bullet\right)\right] /\left[1+\left(q_{i} / p_{i}\right) \cdot \exp \left(-\left(p_{i}+q_{i}\right) \cdot \bullet\right)\right]$ 이다.

또한 $\tau_{i}(i=2,3,4)$ 는 $\mathrm{i}$-세대 DRAM이 반도체 시장에 도입된 시기이며, $t<\tau_{i}$ 에 대해서 $F_{i}\left(t-\tau_{i}+1\right)=0$ 이다.

식(2.12)부터 식(2.15)까지로 구성된 연립방정식 모형은 $4 \mathrm{k}$ (1세대), $16 \mathrm{k}(2$ 세대), $64 \mathrm{k}$ (3세대), $256 \mathrm{k}$ (4세대)가 존재하는 1974년 1분기부터 1985년 2분기까지의 전세계 DRAM 반도체 시장 에서 세대간 대체과정과 세대별 확산과정을 반영하여 각 세대의 동태적 판매량을 묘사하고 있다. 앞에서 언급한 3 개의 세대들, 즉 $4 \mathrm{k}, 16 \mathrm{k}, 64 \mathrm{k}$ 만이 존재하는 기간동안에 각 세대의 동태 적 판매량을 표현하는 수식들을 구해보면, 식(2.12), 식(2.13) 그리고 식(2.14)에서 $F_{4}\left(t-\tau_{4}+1\right)$ 을 0 으로 놓은 식으로 구성된 연립방정식 모형이 된다. 또한 2 개의 세대들, 즉 $4 \mathrm{k}$ 와 $16 \mathrm{k}$ 만이 존재하는 기간동안에 1 세대와 2 세대의 동태적 판매량을 표현하는 수식들을 구해보면, 식(2.12)와 식(2.13)에서 $F_{3}\left(t-\tau_{3}+1\right)$ 올 0 으로 놓은 식으로 구성된 연립방정식 모형이고, 이는 식(2.10) 그리고 식(2.11)과 동일함을 알 수 있다.

Norton and Bass(1987)는 다세대 기술제품들이 같은 제품군(product class)에 속해 있으므로 세대별 확산과정이 유사하리라 생각하고, $F_{i}(\bullet)$ 에서 $p_{i}$ 와 $q_{i}$ 를 세대 $\mathrm{i}$ 에 관계없이 모두 동일한 것(즉 모든 $\mathrm{i}$ 에 대해서 $p_{i}=p$ 와 $q_{i}=q$ )으로 가정하고서 모수들(parameters)을 추정 하였다. 이렇게 함으로써 추정해야 할 모수들의 수는 $\mathfrak{n}$ 개의 세대들이 존재하는 시장의 경우 에 $(2 n+n)$ 으로부터 $(2+n)$ 으로 대폭 감소시킬 수 있었고, 추정에 사용할 자료의 수가 적은 경 우에 톡히 효율적인 가정임을 제안하였다. 또한 모든 세대에 대해서 $p$ 와 $q$ 가 동일하다는 가정하에서 광범위한 제품군들의 실제판매량 자료에 모형을 적용해 본 결과가 상당히 만족 스럽다는 것을 그들의 후속연구(Norton and Bass 1992)에서 보여주었다. 그러나 본 연구에서는 뒤에 언급할 Jun and Park(1999)의 모형들과의 DRAM 반도체 판매량 자료를 사용한 경헙적 비교를 위해서, Jun and Park의 모형에 포함된 모수들의 의미와 수에 일치되도톡 식(2.12)부터 식(2.15)까지로 구성된 Norton and Bass의 모형에서 $p_{i}$ 는 세대 $\mathrm{i}$ 에 관계없이 모두 동일하게, 즉 모든 $\mathrm{i}$ 에 대해서 $p_{i}=p$ 로 가정하지만 $q_{i}$ 는 세대 $\mathrm{i}$ 에 따라서 다를 수 있는 것으로 간주 하고서 추정모형(estimation model)올 설정한다. 그리고 이를 NBI 모형으로 명명한다. 결과적 으로 NB1 모형에는 9 개의 모수들(즉 1 개의 $p, 4$ 개의 $q_{i}$, 그리고 4 개의 $m_{i}$ )이 포함되어 있 다. NB1 모형의 추정절차로 Norton and Bass(1987)와 마찬가지로 SAS(1993)의 MODEL procedure에 나오는 비선형 3단계 최소자숭법(nonlinear three-stage least squares method)을 사용 한다.

\subsubsection{Mahajan and Muller(1996)의 연구}

Mahajan and Muller(1996)는 IBM 메인쯔레임 컴퓨터(mainframe computer)의 1955년부터 1978 년까지 4개의 세대들, 즉 1세대(vacuum tubes, $\tau_{1}=1995$ ), 2세대(transistors, $\tau_{2}=1959$ ), 3세 대(360 family(integrated circuits), $\tau_{3}=1965$ ), 4세대(370 family(silicon chips), $\tau_{4}=1971$ )에 대 한 수요 분석을 위해서 Bass(1969)의 기본모형에 기반을 두고 세대간 대체과정과 세대별 확 
산과정을 동시에 포착할 수 있는 모형을 제시하였다. IBM 메인프레임의 확산과 대체 과정에 서 수용자(adopters)는 개인보다는 조직(organization)이 될 것이지만 최종 사용자(end user)로서 DRAM 반도체와는 달리 여러 단위(multiple units)를 반복구매하기 보다는 한 단위(one unit)를 최초구매하여 더 신규세대로의 대체가 있기 전에는 수용한 세대를 반복적으로 사용할 것이 다. Mahajan and Muller(1996)가 IBM 메인프레임의 수요 분석을 위해서 사용한 자료는 각 세 대별로 실제로 시스템을 사용중인(systems in use) 누적 수용자들(cumulative adopters)의 수를 동태적으로 관찰한 자료이다. IBM 메인프레임의 1세대만이 존재하는 기간동안에는 실제로 시스템을 사용중인 누적 수용자들의 수는 1세대의 누적 판매량(cumulative sales)과 일치하므 로 Bass의 기본모형을 그대로 적용할 수 있다. 하지만 1세대보다 더 신규세대들의 시장도입 이후(즉 다세대 상황)에는 이전세대를 사용하였던 누적 수용자들이 더 신규세대로 업그레이 드가 발생하는 대체과정으로 인하여 각 세대롤 실제로 사용중인 누적 수용자들의 수는 각 세대의 누적 판매량과 일치하지 않게 되고, 이는 이전세대의 누적 수용자들의 수가 신규세 대의 시장도입 이후 어느 시기에는 감소하기 시작하는 종 모양의 곡선으로 나타나게 된다. 이러한 IBM 메인프레임의 확산과 대체 과정을 모형화하기 위해서 Mahajan and Muller(1996, P.114)는 <그림 2>와 같은 4개의 세대들에 걸친 수용자들(adopters)의 동태적 흐름(flow dynamics)을 제시하였다.

<그림 2>4개의 세대들에 결친 수용자들의 동태적 흐름

(a) 1 세대 시장도입(1세대만이 존재; $\tau_{1} \leq t<\tau_{2}$ )

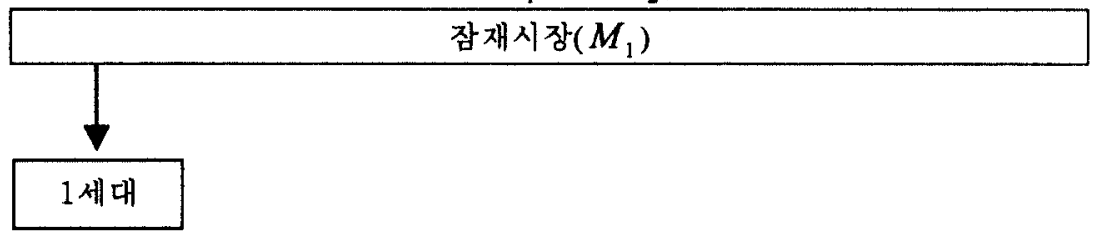

(b) 2 세대 시장도입(1세 대와 2세 대가 존재; $\tau_{2} \leq t<\tau_{3}$ )

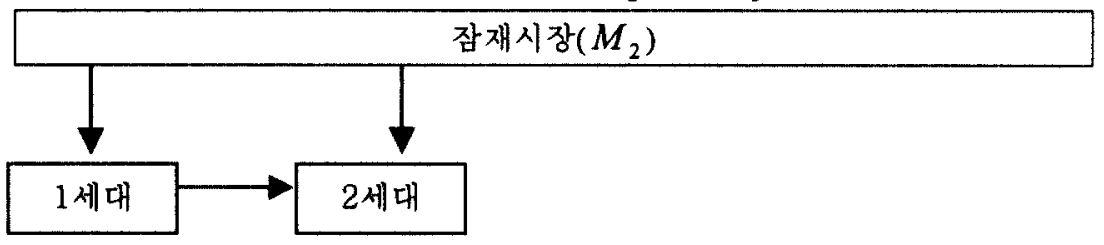

(c) 3 세대 시장도입(1세대, 2세대, 3 세대가 존재; $\tau_{3} \leq t<\tau_{4}$ )

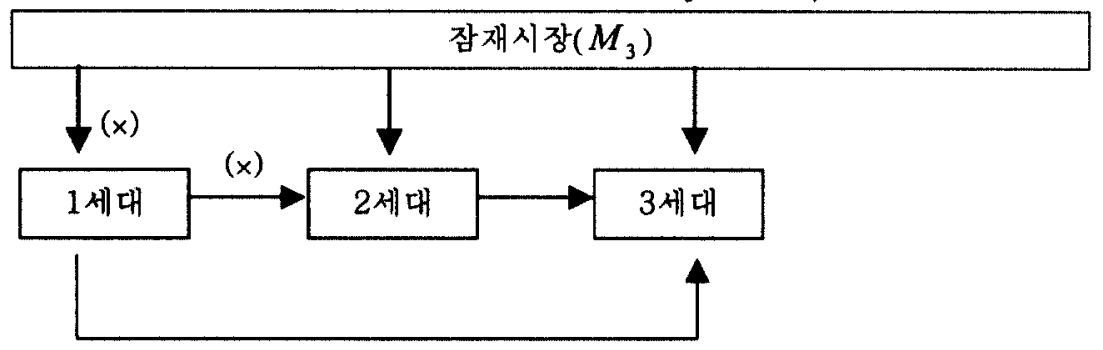


(d) 4 세대 시장도입(1세대, 2 세대, 3 세대, 4 세대가 존재; $t \geq \tau_{4}$ )

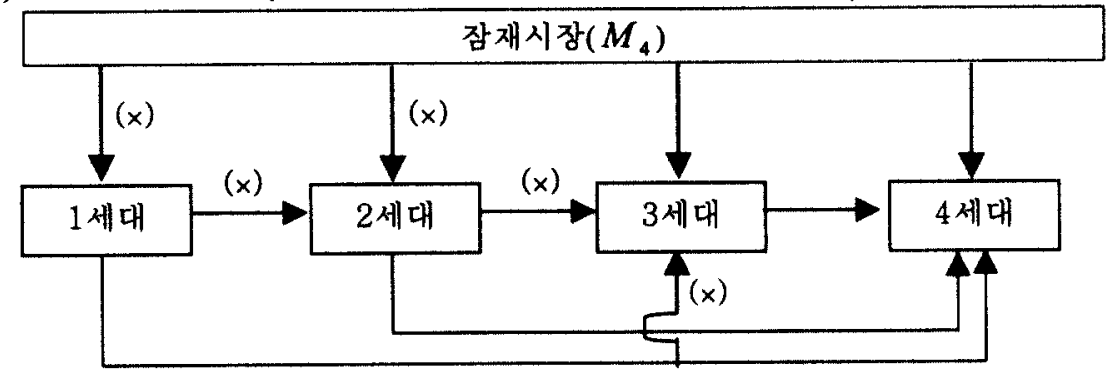

<그림 2>에서의 $M_{i}$ 는 앞에서 살펴본 Norton and Bass(1987)의 모형(즉 NB1)에서의 i-세대 잠재시장 크기를 나타내는 $m_{i}=M_{i} r_{i}$ 와는 두 가지 점에서 다르다. 첫째, $\mathrm{NB} 1$ 모형은 반복 구매 확산모형에 기초률 두고 있기 때문에 NB1 모형에서의 $m_{i}$ 에는 수용자들(adopters)의 i세대에 대한 평균 기간당 소비율 $\left(r_{i}\right)$ 이 반영되어 있다. 둘째, $\mathrm{NB} 1$ 모형에서 $m_{i}$ 를 구성하는 또 다른 요소인 $M_{i}$ 는 i-세대 이전에는 존재하지 않았다가 i- 세대에 의해서 비로소 새탑게 추가된 잠재 수용자들(incremental potential adopters)의 수를 나타내지만, Mahajan and Muller 모 형(즉 <그림 2>)에서의 $M_{i}$ 는 i-세대 이전에도 존재하였지만 이전세대들올 아직까지 수용하 지 않은 잠재 수용자들을 포합하여 $\mathrm{i}$-세대에 의해서 비로소 새롭게 추가된 잠재 수용자들의 합을 나타낸다.

Mahajan and Muller 모형은 <그림 2>에서 보여준 수용자들의 동태적 흐름에 기초하고 있다. 즉 $\mathrm{t}$ 期에 $\mathrm{i}$-세대를 실제로 사용중인 수용자수의 중감은 $\mathrm{t}$ 期 이전에는 어떠한 세대들도 수 용하지 않았던 잠재 수용자들 중에서 $\mathrm{i}$-세대를 최초로 수용하는 수요(first-purchase demand)와 $\mathrm{t}$ 期 이전에는 $\mathrm{i}$-세대의 이전세대들을 사용하였던 이전세대 수용자들 중에서 $\mathrm{i}$-세대로의 업그 레이드 수요(upgrade demand)의 합에서 $\mathrm{t}$ 期 이전에는 $\mathrm{i}$-세대를 사용하였던 $\mathrm{i}-$ 세대 수용자들 중에서 $\mathrm{i}$-세대보다 더 신규세대들로의 업그레이드 수요를 차감한 것으로 나타낼 수 있다. 가 령 <그림 2-d>에서 최근 세대인(즉 더 이상 신규세대가 존재하지 않는) 4세대를 $\mathrm{t}$ 期에 실제 로 사용중인 수용자들은 (t-1)期에 4세대를 실제로 사용중인 누적 수용자들에 더하여 (1)전에 는 1 세대를 사용하였지만 2 세대와 3 세대를 건너뛰고(leapfrog) $t$ 期에 4 세대로 업그레이드, (2) 전에는 2 세대를 사용하였지만 3 세대를 건너뛰고 $\mathrm{t}$ 期에 4 세대로 업그레이드, (3)전에는 3 세대 를 사용하였지만 $\mathrm{t}$ 期에 4 세대로 업그레이드, (4)전에는 어떠한 세대도 수용하지 않았다가 $\mathrm{t}$ 期에 4세대를 최초로 수용한 자들(first-time adopters)의 합으로 구성된다. 즉 <그림 2>에서의 모든 동태적 흐름을 수식으로 모형화하게 되면 너무 많은 모수들(parameters)이 존재하게 되 어 추정상의 어려움이 발생하므로 Mahajan and Muller(1996)는 최근 세대가 i-세대인 기간동안 (즉 $\tau_{i} \leq t<\tau_{i+1}$ )에 발생하는 다세대간 확산과 대체 과정에 대하여 다음과 같은 가정을 한 다. 첫째, 이전까지는 어떠한 세대도 수용하지 않았던 잠재 수용자들(potential adopters)중에서 $\mathbf{t}$ 期에 비로소 최초수용하는자들(first adopters; first-purchase demand)은 가장 최근 세대인 i-세 대와 바로 이전세대인 (i-1)세대에만 각각 $\alpha_{i}$ 와 (1- $\left.\alpha_{i}\right)$ 의 비율로 수용(확산)한다. 둘째, $\mathrm{i}-$ 세 대 이전의 세대들을 사용하였던 수용자들 중에서 $\mathrm{t}$ 期에 업그레이드 하는 자들(upgraders; upgrade demand)은 가장 최근 세대인 $\mathrm{i}$-세대로만 전환하고 그 비율은 $\alpha_{i}$ 이다. 셋째, 최초구매 
수요(first-purchase demand)와 업그레이드 수요(upgrade demand)에서 발생하는 확산모수들 (diffusion parameters), 즉 각각 $\left(p_{i}, q_{i}\right)$ 와 $\left(p_{i}{ }^{\prime}, q_{i}{ }^{\prime}\right)$ 은 서로 다르지만 모든 i에 대해서는 동 일하다(즉 최초구매 수요: 모든 $\mathrm{i}$ 에 대해서 $p_{i}=p$ 와 $q_{i}=q$; 업그레이드 수요: 모든 $\mathrm{i}$ 에 대해서 $p_{i}^{\prime}=p^{\prime}$ 와 $q_{i}^{\prime}=q^{\prime}$ ). 이러한 가정 하에서 <그림 $2>$ 에서 보여준 4 개 세대들에 대한 학산과 대체 과정을 반영한 Mahajan and Muller(1996)의 모형을 수식으로 표현하면 다음과 같 다.

1 세대만 존재하는 기간 $\left(\tau_{1} \leq t<\tau_{2}\right)$ :

$$
Y_{1}(t)-Y_{1}(t-1)=\left[p+\left(q / M_{1}\right) Y(t-1)\right]\left[M_{1}-Y(t-1)\right]
$$

1 세대와 2 세대만 존재하는 기간 $\left(\tau_{2} \leq t<\tau_{3}\right)$ :

$$
\begin{aligned}
Y_{2}(t)-Y_{2}(t-1) & =\alpha_{2}\left[p+\left(q / M_{2}\right) Y(t-1)\right]\left[M_{2}-Y(t-1)\right] \\
& +\alpha_{2}\left[p^{\prime}+\left(q^{\prime} / M_{2}\right) Y_{2}(t-1)\right] Y_{1}(t-1) \\
Y_{1}(t)-Y_{1}(t-1)= & \left(1-\alpha_{2}\right)\left[p+\left(q / M_{2}\right) Y(t-1)\right]\left[M_{2}-Y(t-1)\right] \\
& -\alpha_{2}\left[p^{\prime}+\left(q^{\prime} / M_{2}\right) Y_{2}(t-1)\right] Y_{1}(t-1)
\end{aligned}
$$

1 세대, 2 세대, 3 세대만 존재하는 기간 $\left(\tau_{3} \leq t<\tau_{4}\right)$ :

$$
\begin{aligned}
Y_{3}(t)-Y_{3}(t-1)=\alpha_{3}\left[p+\left(q / M_{3}\right) Y(t-1)\right]\left[M_{3}-Y(t-1)\right] & \\
& +\alpha_{3}\left[p^{\prime}+\left(q^{\prime} / M_{3}\right) Y_{3}(t-1)\right]\left[Y_{1}(t-1)+Y_{2}(t-1)\right] \\
Y_{2}(t)-Y_{2}(t-1) & =\left(1-\alpha_{3}\right)\left[p+\left(q / M_{3}\right) Y(t-1)\right]\left[M_{3}-Y(t-1)\right] \\
& -\alpha_{3}\left[p^{\prime}+\left(q^{\prime} / M_{3}\right) Y_{3}(t-1)\right] Y_{2}(t-1) \\
Y_{1}(t)-Y_{1}(t-1) & =-\alpha_{3}\left[p^{\prime}+\left(q^{\prime} / M_{3}\right) Y_{3}(t-1)\right] Y_{1}(t-1)
\end{aligned}
$$

1 세대, 2세대, 3 세대, 4세대 모두가 존재하는 기간 $\left(t>\tau_{4}\right)$ :

$$
\begin{aligned}
& Y_{4}(t)-Y_{4}(t-1)=\alpha_{4}\left[p+\left(q / M_{4}\right) Y(t-1)\right]\left[M_{4}-Y(t-1)\right] \\
& +\alpha_{4}\left[p^{\prime}+\left(q^{\prime} / M_{4}\right) Y_{4}(t-1)\right]\left[Y_{1}(t-1)+Y_{2}(t-1)+Y_{3}(t-1)\right] \\
& \begin{aligned}
Y_{3}(t)-Y_{3}(t-1) & =\left(1-\alpha_{4}\right)\left[p+\left(q / M_{4}\right) Y(t-1)\right]\left[M_{4}-Y(t-1)\right] \\
& -\alpha_{4}\left[p^{\prime}+\left(q^{\prime} / M_{4}\right) Y_{4}(t-1)\right] Y_{3}(t-1)
\end{aligned}
\end{aligned}
$$


$Y_{1}(t)-Y_{1}(t-1)=-\alpha_{4}\left[p^{\prime}+\left(q^{\prime} / M_{4}\right) Y_{4}(t-1)\right] Y_{1}(t-1)$

여기서 $Y(t-1)=Y_{1}(t-1)+Y_{2}(t-1)+Y_{3}(t-1)+Y_{4}(t-1)$ 이고, $Y_{i}(t)$ 와 $Y_{i}(t-1)$ 은 각각 $\mathrm{t}$ 期와 (t-1) 期에 i-세대를 실제로 사용중인 누적 수용자들의 수로서 관찰 가능하여 IBM 메인 프레임의 수요 분석 시에 사용된 자료이다.

Mahajan and Muller가 단순화 가정(simplifying assumptions)을 동원하여 IBM 메인프레임의 4 개 세대들에 결친 확산과 대체과정을 묘사한 모형(즉 식(2.16)부터 식(2.25)까지)에는 결과적 으로 11 개의 모수들(즉 3 개의 $\alpha_{i}$,4개의 $M_{i}$, 그리고 $p, q, p^{\prime}, q^{\prime}$ ) 이 포함되어 있다.

\subsubsection{Jun and Park(1999)의 연구}

Jun and Park(1999)은 다세대 기술제품들의 확산과 대체 과정을 동시에 포착하기 위해서 기 존 연구들(가령 Norton and Bass 1987; Mahajan and Muller 1996)과는 달리 소비자 선택행동 (consumer choice behavior)에 기반을 둔 선택확률들(choice probabilities)과 마케팅 믹스 변수들 의 효과를 확산효과(diffusion effects)와 함께 반영한 모형을 개발하였다. 본 연구에서는 각 모 형의 이론적인 틀과 가정을 비교·분석하고 <그림 1>에서 보여준 전세계 DRAM 출하량(반매 량) 자료를 사용하여 모형간 경험적 비교에 목적을 두고 있으므로 Jun and Park(1999)의 모형 에서 마케팅 믹스 변수들의 효과 부분은 제외하고 그들의 모형을 살펴보기로 한다.

Jun and Park(1999)은 최종 사용자(end user)를 구매자 겸 신제품 수용자(adopter)로 간주하고, 내구성 기술제품올 연구 대상으로 하므로 소비자가 구매하기로 선택한다면 단지 한 단위 (one unit)만을 구매한다고 가정한다. 또한 각 시기(time period)에 소비자의 선택은 이전 시기 들(previous periods)의 선택과는 독립적이고 선택시기에 힉득가눙한 세대들에 대한 선택효용

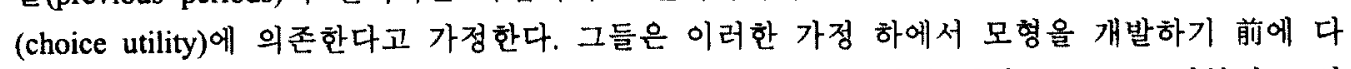
세대 기술제품에서 볼 수 있는 판매량 자료(sales data)를 두 가지 타입(type)으로 양분하고 있 다. 즉 최초구매 수요(first purchase demand)와 업그레이드 수요(upgrade demand)를 구분할 수 있는 자료를 타입 I(type I)으로 그리고 최초구매 수요와 업그레이드 수요를 구분할 수 없는 자료를 타입 II(type II)로 명명하였다. 그들은 Norton and Bass(1987)의 모형과 Mahajan and Muller(1996)의 모형은 단지 타입 I의 자료에만 적용할 수 있다고 주장하면서, 타입 I 자료와 타입 II 자료에 각각 적용할 수 있는 그들의 타입 I 모형과 타입 II 모형올 개발하였다. 가령 Mahajan and Muller(1996)가 사용한 자료, 즉 IBM 메인프래임의 각 세대별로 실제로 시스템을 사용중인 누적 수용자들의 수를 관찰한 자료는 타입 I의 자료이고 Norton and Bass(1987)가 사용한 자료, 즉<그림 1>에서 보여준 전세계 DRAM 반도체의 세대별 출하량 자료는 타입 II의 자료로 예를 들고서 그들의 타입 I 모형과 타입 II 모형을 각각 적용하였다.

본 논문에서는 <그림 1 에서 보여준 4 개의 세대들에 걸쳐서 발생한 DRAM 출하량 자료 에 적용하기 위하여 추정 시에 궁극적으로 사용한 Jun and Park의 타입 I 모형과 타입 II 모 형을 제시한다. 먼저 그들의 다세대 확산모형(multigeneration diffusion model)이 기반을 두고 있는 소비자들의 선택행동의 결과인 선택확률은 로짓모형(logit model; Ben-Akiva and Lerman 1985 참고)로부터 도출하였다. 가령 가장 최근 세대가 $\mathrm{i}$-세대인 기간 동안 $\left(\tau_{i} \leq t<\tau_{i+1}\right)$ 에 아직까지 어떠한 세대도 수용하지 않은 소비자가 $\mathrm{t}$ 期에 비로소 $\mathrm{k}$-세대 $(1 \leq k \leq i)$ 를 최초로 수용할 선택확률 $\left(p_{k}(t)\right)$ 은 다음과 같다. 


$$
p_{k}(t)=\frac{\exp \left(V_{k}(t)\right)}{\exp \left(V_{0}(t)\right)+\exp \left(V_{1}(t)\right)+\Lambda+\exp \left(V_{i}(t)\right)}
$$

여기서 $V_{0}(t)=c$ 로서 소비자가 $\mathrm{t}$ 期에도 여전히 잠재 수용자로서 머무률 때의 효용이고 $V_{k}(t)=q_{k}\left(t-\tau_{k}+1\right)$ 으로서 소비자가 $\mathrm{t}$ 期에 $\mathrm{k}$-세대를 수용함으로써 언게 되는 효용을 나 타낸다. $V_{k}(t)$ 의 표현에서 시간변수(즉 $\left(t-\tau_{k}+1\right)$ )는 다세대 제품들(multigenerational products)에서의 확산효과(diffusion effects)를 반영하고 있다. 즉 $\mathrm{k}$-세대가 시장에 도입된 이후 에 처음에는 k-세대에 대한 정보가 불확실하지만 시간이 흐름에 따라서 구전 커뮤니케이션 둥을 통하여 $\mathrm{k}$-세대에 대한 불확실성이 감소되므로 소비자들의 $\mathrm{k}$-세대에 대한 효용은 시간 이 지남에 따라서 통상적으로 중가한다는 것을 반영한다. 또한 $V_{k}(t)$ 의 표현에서 모수 (parameter)인 $q_{k}$ 는 k-세대의 품질(quality)을 반영하는 것으로서 일반적으로 더 신규세대일수 록 단조중가한다고 가정할 수 있다. 또한 가장 최근 세대가 $\mathrm{i}$-세대인 기간동안 $\left(\tau_{i} \leq t<\tau_{i+1}\right)$ 에 이전세대인 $\mathrm{j}$-세대(j<i)를 수용하여 사용하였던 소비자가 $\mathrm{t}$ 期에 더 신규 세대인 $\mathrm{k}$-세대 $(j<k \leq i)$ 로 업그레이드할 선택확률 $\left(p_{k}{ }^{\prime}(t)\right)$ 은 다음과 같다.

$$
p_{k}{ }^{\prime}(t)=\frac{\exp \left(V_{k}(t)\right)}{\exp \left(V_{j}(t)\right)+\exp \left(V_{j+1}(t)\right)+\Lambda+\exp \left(V_{i}(t)\right)}
$$

Jun and Park은 타입 I 모형을 개발함에 있어서 Mahajan and Muller(1996)의 동태적 흐름(flow dynamics), 즉 <그림 2>를 사용하고 추정해야 할 모수들의 수를 줄이기 위해서 Mahajan and Muller(1996)와 마찬가지로 최초구매(first purchase)는 가장 최근의 두 개 세대들에서만 발생하 고 업그레이드는 가장 최근 세대로의 전환으로만 발생한다고 가정한다. 즉 이런 가정 하에 서 식(2.26)과 식(2.27)은 각각 다음의 식(2.28)과 식(2.29)로 표현된다.

$k=(i-1), i$ 에 대해서

$$
\begin{aligned}
& p_{k}(t)=\frac{\exp \left(V_{k}(t)\right)}{\exp \left(V_{0}(t)\right)+\exp \left(V_{i-1}(t)\right)+\exp \left(V_{i}(t)\right)} \\
& p_{i}^{\prime}(t)=\frac{\exp \left(V_{i}(t)\right)}{\exp \left(V_{j}(t)\right)+\exp \left(V_{i}(t)\right)}
\end{aligned}
$$

최종적으로 구해낸 Jun and Park(1999, p.58)의 타입 I 모형은 Mahajan and Muller(1996)의 모형 (즉 식(2.16)부터 식(2.25)까지)에서 흐름율들(flow rates)을 식(2.28)과 식(2.29)로 대체한 결과이 며 다음과 같은 식들로 표현된다.

1 세대만 존재하는 기간 $\left(\tau_{1} \leq t<\tau_{2}\right)$ :

$$
Y_{1}(t)-Y_{1}(t-1)=\left[M_{1}-Y(t-1)\right] \frac{\exp \left(V_{1}(t)\right)}{\exp \left(V_{0}(t)\right)+\exp \left(V_{1}(t)\right)}
$$


1 세대와 2 세대만 존재하는 기간 $\left(\tau_{2} \leq t<\tau_{3}\right)$ :

$$
\begin{gathered}
Y_{2}(t)-Y_{2}(t-1)=\left[M_{2}-Y(t-1)\right] \frac{\exp \left(V_{2}(t)\right)}{\exp \left(V_{0}(t)\right)+\exp \left(V_{1}(t)\right)+\exp \left(V_{2}(t)\right)} \\
+Y_{1}(t-1) \frac{\exp \left(V_{2}(t)\right)}{\exp \left(V_{1}(t)\right)+\exp \left(V_{2}(t)\right)} \\
Y_{1}(t)-Y_{1}(t-1)=\left[M_{2}-Y(t-1)\right] \frac{\exp \left(V_{1}(t)\right)}{\exp \left(V_{0}(t)\right)+\exp \left(V_{1}(t)\right)+\exp \left(V_{2}(t)\right)} \\
-Y_{1}(t-1) \frac{\exp \left(V_{2}(t)\right)}{\exp \left(V_{1}(t)\right)+\exp \left(V_{2}(t)\right)}
\end{gathered}
$$

1세대, 2 세대, 3 세대만 존재하는 기간 $\left(\tau_{3} \leq t<\tau_{4}\right)$ :

$$
\begin{aligned}
Y_{3}(t)-Y_{3}(t-1)= & {\left[M_{3}-Y(t-1)\right] \frac{\exp \left(V_{3}(t)\right)}{\exp \left(V_{0}(t)\right)+\exp \left(V_{2}(t)\right)+\exp \left(V_{3}(t)\right)} } \\
& +Y_{1}(t-1) \frac{\exp \left(V_{3}(t)\right)}{\exp \left(V_{1}(t)\right)+\exp \left(V_{3}(t)\right)} \\
& +Y_{2}(t-1) \frac{\exp \left(V_{3}(t)\right)}{\exp \left(V_{2}(t)\right)+\exp \left(V_{3}(t)\right)} \\
Y_{2}(t)-Y_{2}(t-1)= & {\left[M_{3}-Y(t-1)\right] \frac{\exp \left(V_{2}(t)\right)}{\exp \left(V_{0}(t)\right)+\exp \left(V_{2}(t)\right)+\exp \left(V_{3}(t)\right)} } \\
& -Y_{2}(t-1) \frac{\exp \left(V_{3}(t)\right)}{\exp \left(V_{2}(t)\right)+\exp \left(V_{3}(t)\right)} \\
Y_{1}(t)-Y_{1}(t-1)= & -Y_{1}(t-1) \frac{\exp \left(V_{3}(t)\right)}{\exp \left(V_{1}(t)\right)+\exp \left(V_{3}(t)\right)}
\end{aligned}
$$

1 세대, 2세대, 3세대, 4세대 모두가 존재하는 기간 $\left(t>\tau_{4}\right)$ :

$$
Y_{4}(t)-Y_{4}(t-1)=\left[M_{4}-Y(t-1)\right] \frac{\exp \left(V_{4}(t)\right)}{\exp \left(V_{0}(t)\right)+\exp \left(V_{3}(t)\right)+\exp \left(V_{4}(t)\right)}
$$




$$
\begin{aligned}
& +Y_{1}(t-1) \frac{\exp \left(V_{4}(t)\right)}{\exp \left(V_{1}(t)\right)+\exp \left(V_{4}(t)\right)}+Y_{2}(t-1) \frac{\exp \left(V_{4}(t)\right)}{\exp \left(V_{2}(t)\right)+\exp \left(V_{4}(t)\right)} \\
& +Y_{3}(t-1) \frac{\exp \left(V_{4}(t)\right)}{\exp \left(V_{3}(t)\right)+\exp \left(V_{4}(t)\right)}
\end{aligned}
$$$$
Y_{3}(t)-Y_{3}(t-1)=\left[M_{4}-Y(t-1)\right] \frac{\exp \left(V_{3}(t)\right)}{\exp \left(V_{0}(t)\right)+\exp \left(V_{3}(t)\right)+\exp \left(V_{4}(t)\right)}
$$$$
-Y_{3}(t-1) \frac{\exp \left(V_{4}(t)\right)}{\exp \left(V_{3}(t)\right)+\exp \left(V_{4}(t)\right)}
$$$$
Y_{2}(t)-Y_{2}(t-1)=-Y_{2}(t-1) \frac{\exp \left(V_{4}(t)\right)}{\exp \left(V_{2}(t)\right)+\exp \left(V_{4}(t)\right)}
$$$$
Y_{1}(t)-Y_{1}(t-1)=-Y_{1}(t-1) \frac{\exp \left(V_{4}(t)\right)}{\exp \left(V_{1}(t)\right)+\exp \left(V_{4}(t)\right)}
$$

여기서 $V_{0}(t)=c$ 이고, $k=1,2,3,4$ 에 대해서 $V_{k}(t)=q_{k}\left(t-\tau_{k}+1\right)$ 이다.

Jun and Park(1999)의 타입 I 모형(즉 식(2.30)부터 식(2.39)까지)에는 결과적으로 9개의 모수 들(즉 1개의 $c, 4$ 개의 $q_{i}$, 그리고 4 개의 $M_{i}$ )이 포함되어 있다. Jun and Park은 타입 I 모형올 타입 I 자료의 예로서 분류한 IBM 메인프레임 컴퓨터 자료에 적용하였지만, 본 연구에서는 타입 I 모형의 의미를 변화시켜서 그들이 타입 II 자료의 예로서 분류한 전세계DRAM 반도 체 출하량 자료에 적용하려고 한다. Jun and Park(1999)은 신제품의 최중 사용자(end user)를 수 용자(adopter)로 간주하고 단지 한 단위(one unit)만을 구매할 수 있다는 가정 하에서 타입 I 모형을 개발하였기 때문에 그러한 가정 하에서는 최초구매 수요와 업그레이드 수요를 구분 할 수 없는 전세계 DRAM 반도체 판매량 자료에는 타입 I 모형을 적용할 수 없고 그들이 새로 개발한 타입 II 모형을 적용하여야 한다고 주장하였다. 그러나 타입 I 모형에서의 가정 을 변화시켜서, 즉 DRAM 반도체의 수용자로 최종 사용자들이 아닌 Norton Bass(1987)와 마 찬가지로 웅용기기(제조회사)들을 수용자로 간주하고 웅용기기들은 단지 한 단위가 아닌 여 러 단위들을 반복구매를 한다고 가정하면, 이러한 가정 하에서의 타입 I 모형(즉 식(2.30)부 터 식(2.39)까지)은 전세계 DRAM 반도체 판매량 자료에 적용할 수 있게 되고 이 모형을 본 연구에서는 JP1으로 명명한다. JP1 모형에서 $Y_{i}(t)$ 와 $Y_{i}(t-1)$ 은 각각 $\mathrm{t}$ 期와 $(\mathrm{t}-1)$ 期에 $\mathrm{i}$-세 대 DRAM 반도체를 반복구매 중인 누적수용자들의 수에 평균 반복 구매율(average repeat purchase rate)을 곱한 것으로서 관찰가능한 $\mathrm{t}$ 期와 $(\mathrm{t}-1)$ 期의 $\mathrm{i}$-세대 DRAM 반도체의 판매량 을 나타낸다. 또한 반복구매 확산모형인 JP1 모형에서의 $M_{i}$ 는 Jun and Park 의 원래의 타입 I 모형에서의 $M_{i}$ 와는 그 의미가 달라진다. 
Jun and Park(1999)은 최종 사용자를 신제품의 수용자로 간주하고 단지 한 단위만을 구매할 수 있다는 그들의 가정 하에서는 전세계 DRAM 반도체 판매량 자료와 같은 타입 II 자료에 서는 최초구매 수요와 업그레이드 수요를 분간할 수 없기 때문에 타입 I 자료와는 달리 잠 재시장(market potential)을 정의해야 한다고 주장한다. 즉 IBM 메인프레임 컴퓨터 자료와 같 은 타입 I 자료에서는 각 세대별로 실제로 제품을 사용중인 누적 수용자들의 수률 동태적으 로 관찰할 수 있으므로 최초구매 수요와 업그레이드 수요를 구분할 수 있지만, DRAM 반도 체 판매량 자료와 같은 타입 II 자료에서는 최초구매자들과 업그레이더들이 서才여 있는 각 세대별 판매량을 단지 관찰할 수 있으므로 이 경우에는 잠재시장을 모든 세대들에 대한 누 적 수용자들이 아닌 누적 판매량의 궁극적인 값들(ultimate values)의 충수(total number)로 정의 한다. 이러한 잠재시장의 정의에는 한 최종 사용자가 한번만 잠재시장의 크기에 계산되는 것이 아니라 어느 세대를 최초구매하는 것올 포합하여 신규세대들로 업그레이드하는 회수만 큼 여러 번 잠재시장의 크기에 계산되어진다.

타입 II 판매량 자료에서 가장 최근 세대가 $\mathrm{i}$-세대인 기간동안 $\left(\tau_{i} \leq t<\tau_{i+1}\right)$ 에 잠재시장 의 크기를 $N_{i}$ 로, 그리고 (t-1) 期까지의 모든 세대들에 대한 누적 판매량을 $Y(t-1)$ 으로 ㅎㅎㅎ 으면, $\mathbf{t}$ 期의 잠재 구매자들(즉 잠재적 최초구매자들과 업그레이더들을 포함)의 총수는 $\left(N_{i}-Y(t-1)\right)$ 이 된다. 또한 타입 II 판매량 자료에서는 최초구매자들과 업그레이더들이 구 분될 수 없으므로 잠재적 최초구매자들과 업그레이더들에게 모두 적용할 수 있는 $\mathbf{t}$ 期의 $\mathbf{k}-$ 세대 $(1 \leq k \leq i)$ 선택확률 $\left(p_{k}(t)\right)$ 을 식(2.26)과 같이 나타내면 타입 II 모형은 다음과 같이 표현된다.

$\mathrm{j}$-세대가 가장 최근 세대(즉 1 세대, $\cdots, \mathrm{i}$-세대가 존재)인 기간 $\left(\tau_{i} \leq t<\tau_{i+1}\right)$ :

$$
k=1, \Lambda, i \text { 에 대해서 } S_{k}(t)=\left(N_{i}-Y(t-1)\right) \frac{W_{k}(t)}{W_{0}(t)+W_{1}(t)+\Lambda+W_{i}(t)}
$$

여기서 $W_{0}(t)=\exp (c)$,

$$
\begin{aligned}
& W_{k}(t)=\exp \left(V_{k}(t)\right)=\exp \left(q_{k}\left(t-\tau_{k}+1\right)\right), \\
& Y(t)=Y(t-1)+S_{1}(t)+\Lambda+S_{i}(t) \text { 이고, } \\
& S_{k}(t) \text { 는 k-세대 }(1 \leq k \leq i) \text { 의 } \mathrm{t} \text { 期 판매량이다. }
\end{aligned}
$$

식(2.40)으로 표현된 Jun and Park 의 타입 II 모형을 본 연구에서는 JP2로 명명하고, <그림 $1>$ 에 주어진 전세계 DRAM 반도체 출하량 자료에 적용한다. 이 경우에 JP2 모형에서 추정 해야 할 모수들의 수는 NB1 모형, JP1 모형에서와 같이 모두 9 개(즉 1 개의 $c, 4$ 개의 $q_{i}$, 그 리고 4 개의 $N_{i}$ )이지만, 잠재시장의 크기(즉 NB1 모형에서는 $m_{i}, \mathrm{JP1}$ 모형에서는 $M_{i}, \mathrm{JP} 2$ 모형에서는 $N_{i}$ 로 표현됨)는 모형간에 그 의미가 서로 상이하다. 또한 NB1 모형과 JP2 모형 에서는 $\mathrm{t}$ 期의 $\mathrm{k}$-세대 DRAM 반도체의 판매량을 $S_{k}(t)$ 로 표현했지만, JP1 모형에서는 $Y_{k}(t)$ 로 표현했음에 주의를 기울이면 JP1 모형과 JP2 모형의 상이함을 알 수 있다. JP1 모형과 JP2 모형의 추정절차로 Jun and Park(1999)과 마찬가지로 비선형 최소자숭법(nonlinear least 
squares method)을 사용한다.

\section{3. 경혐적 비교}

본 장에서 사용하는 자료는 <그림 1>에서 보여준 1974년 1분기부터 1985년 2분기까지 걸 친 46개의 분기별 전세계 DRAM 반도체 출하량 자료이다. <그립 $1>$ 에서 $16 \mathrm{k}, 64 \mathrm{k}$ 그리고 256k DRAM은 1976년 3분기, 1979년 1분기, 1982년 4분기에 각각 시장에 도입되었다. 전세계 DRAM 반도체 출하량 자료를 Jun and Park(1999)은 타입 II 자료의 예로서 분류하고 그듈의 타입 II 모형의 적용에만 사용하였지만, 본 연구에서는 이 자료를 사용하여 앞에서 언급한 Norton and Bass(1987)의 모형(즉 NB1), Jun and Park 의 타입 I 모형에서 최종 사용자들이 아닌 응용기기들을 DRAM 반도체의 수용자들로 간주하고 응용기기들은 단지 한 단위가 아닌 여 러 단위들을 반복구매한다고 가정하여서 그 의미를 변화시킨 모형(즉 JP1)과 Jun and Park이 원래 이 자료에 적용한 타입 II 모형(즉 JP2)의 경험적 비교률 행한다. Jun and Park(1999)은 DRAM 반도체 출하량 자료 외에 비트당 가격(price per bit)자료를 포함하여서 그들의 타입 II 모형에 적용하였지만, 본 연구에서는 모형들의 이론적인 틀과 가정의 차이에 따라서 모형들 이 나타내는 실제 적용에서의 차이를 분석하고자 하므로 분기별 DRAM 출하량 자료만을 분 석에 사용한다.

모형의 모수들의 추정을 통한 모형간의 적합능력(fitting ability)과 추정된 모수들을 활용하 여 모형간의 예측능력(predictive ability)올 비교하기 위하여 Mahajan and Muller(1996), Jun and Park(1999)과 마찬가지로 <그림 1>에서 보여준 1974년 1분기부터 1985년 2분기까지의 $\mathrm{DRAM}$ 반도체 출하량 자료를 2 개의 영역, 즉 1974년 1분기부터 1984년 4분기까지의 적합영 역(fitted region)과 1985년 1분기와 2분기로 구성된 예측영역(forecast region)으로 구분한다. 적 합영역에 속한 44 개의 분기별 자료를 사용하여 각 모형의 모수 추정치들을 구해서 모수들의 액면타당성(parameter face validity)을 살펴보고, 추정된 모수들을 각 모형에 사용하여 44 개의 분기별 출하량에 대한 적합치(fitted values)를 구해내서 실제 관찰치(observed values)와의 적합 도를 비교하고, 마지막으로 추정된 모수들을 각 모형에 사용하여 1985년 1분기와 2분기의 DRAM 반도체 출하량에 대한 예측치(forecasts)를 구해내서 실제 관찰치와의 차이를 통하여 모형간 예측타당성올 비교한다.

NB1 모형의 추정절차로 Norton and Bass(1987)와 마찬가지로 비선형 3단계 최소자숭법 (nonlinear three-stage least squares method)를 사용하고, JP1 모형과 JP2 모형의 추정절차로는 Jun and Park(1999)과 마찬가지로 비선형 최소자숭법(nonlinear least squares method)을 사용한다.<표 1>, <표 2>, <표 3>은 각각 NB1 모형, JP1 모형, JP2 모형의 적합영역에서의 DRAM 출하량 자료에 대한 추정결과를 나타내고 있다.

<표 1 에서 보듯이 DRAM 제품군의 혁신계수인 $p$ 와 각 세대의 모방 계수인 $q_{i}$ 들은 모 두 양(positive)의 값이고, 그 값들이 기존의 확산연구에서 추정한 계수 값들과 거의 같은 범 위(range)에 속하고 있음을 알 수 있다 (Sultan, Farley, and Lehmann, 1990 참고). 또한 각 세대 에 의해서 새톱게 창출.추가된 잠재시장의 크기인 $m_{i}$ 의 값들은 이전세대들보다 신규세대일 
수록 더 크게 나타넜고, 이는 신규세대의 시장도입에 의해서 DRAM 반도체 시장이 급격히 성장하고 있옴을 보여주고 있다. 덧붙혀서 모든 계수추정치들이 $1 \%$ 의 유의수준에서 모두 통계적으로 유의하였다. <표 2>에서 보듯이 JP1 모형의 계수추정치들은 모두 양의 값을 갖 고 있고 그 중에서 $M_{1}$ (p값=0.0201)율 제외한 모든 추정치들이 $1 \%$ 의 유의수준에서 모두 통 계적으로 유의하였다. 또한 Jun and Park(1999)이 기대하둣이 다세대 기술제품들 (multigenerational products)에서의 확산효과(diffusion effects)의 세대간 차이를 반영하는 계수인 $q_{i}$ 의 추정치들은 1 세대률 제외하고는 신규세대일수록 더 커짐(즉 $q_{2}<q_{3}<q_{4}$ ) 을 알 수 있고, 잠재시장의 크기 또한 1 세대 $\left(M_{1}\right)$ 를 제외하고는 NB1 모형과 마찬가지로 신규세대일 수록 더 커짐(즉 $M_{2}<M_{3}<M_{4}$ ) 을 볼 수 있다. <표 3>에서 보듯이 JP2 모형의 계수추정 치들은 모두 양의 값을 갖고 있고, 그 중에서 $N_{1}$ ( $\mathrm{p}$ 값=0.3038)을 제외한 모든 추정치들이 $1 \%$ 의 유의수준에서 통계적으로 유의하다. Jun and Park(1999)이 기대하듯이 확산효과의 세대 간 차이를반영하는 계수인 $q_{i}$ 의 추정치들은 신규세대일수록 이전세대들보다 더 커짐(즉 $q_{1}<q_{2}<q_{3}<q_{4}$ ) 을 불 수 있고, 이것은 신규세대에 대한 소비자들의 선택효용(choice utility)이 시간이 흐름에 따라서 더 빨리 중가함을 나타내준다. 결론적으로 추정된 모수들의 액면타당성(parameter face validity)에 있어서는 NB1 모형, JP1모형, JP2 모형간의 뚜렷한 우열 을 나누어 볼 수 없다.

<그립 3>, <그림 4>, <그립 5>는 각각 NB1 모형, JP1 모형, JP2 모형의 계수추정치들을 각 모 형에 사용하여 구해낸 1974년 1분기부터 1984년 4분기까지의 적합영역에서의 분기별 4 개 세 대들의 DRAM 출하량에 대한 적합치들과 실제관찰치들을 함께 보여주고 있다. <그림 $3>$ 과 <그림 4>에서 보둣이 NB1 모형과 JP1 모형이 제공하는 분기별 4개 세대들의 DRAM 출하량 에 대한 적합치들은 실제 관찰치들과 전반적으로 매우 근접한 양상을 보이고 있다. 그러나 <그림 5>에서 보듯이 JP2 모형이 제공하는 분기별 적합치들 중에서 1세대(4k)와 2세대(16k) 의 적합치들은 실제 관찰치들과는 달리 3 세대(64k)의 시장도입시기(즉 1979년 1분기)에 급격 히 감소하였다가 다시 중가하는 양상을 보이고 있고 또한 4세대(256k)의 시장도입시기(1982 년 2 분기)에는 특히 2 세대와 3 세대의 적합치들이 급격히 감소하였다가 다시 증가하는 양상 을 보임으로써 전반적으로 실제의 관찰치들과는 현격한 차이를 보인다. 각 모형이 적합영역 에서의 DRAM 출하량 자료에 대하여 나타낸 이러한 적합 결과(fitted results)의 차이는 <표 $4>$ 에서 각 모형의 적합영역에서의 SSE(sum of squares error) 값들이 차이로 요약되어 있다. 즉 $\mathrm{JP1}$ 모형을 사용하였을 때의 SSE는 $1.3853 \mathrm{E} 9$ 으로 가장 작은 값을 나타넜고, 그 다옴으로 $\mathrm{NB} 1$ 모형을 사용하였을 때의 SSE가 JP1 모형보다 약간 큰 $2.3126 \mathrm{E} 9$ 을 나타낸 반면에 JP2 모형을 사용하였을 때의 SSE는 JP1 모형, NB1 모형보다 현격하게 큰 $22.1386 \mathrm{E} 9$ 으로 나타났 다. 결론적으로 요약하면 모형의 적합능력에 있어서는 JP1 모형이 NB1 모형보다 약간 우수 하였고, JP2 모형은 JP1 모형과 NB1 모형에 비해서 휠씬 열등한 결과를 보여주었다.

마지막으로 NB1 모형, JP1 모형, JP2 모형의 예측능력을 비교하기 위해서 적합영역에서 추 정된 각 모형의 모수들을 사용하여 $256 \mathrm{k} \mathrm{DRAM}$ 의 1985년 1분기와 2분기(즉 예측영역)의 판 매량을 예측하였고, 그 예측 판매량과 실제 판매량의 절대적 차이들의 평균인 $\mathrm{MAD}$ (mean absolute deviations)올 <표 4>에 보고하였다. <표 4>에서 보듯이 전반적인 예측성과(predictive performance)를 나타내는 예측영역에서의 MAD에 있어서 JPI 모형이 가장 낮은 값(즉 1812) 올 제공하였고, 그 다음으로 JP2 모형(즉 9329)과 NB1 모형(즉10635)의 순서로 나타났다. 그 
러나 각 모형의 분기별 예측 판매량과 실제 판매량을 비교해 보면 JP2 모형은 실제 판매량 보다 휠씬 낮은 수준의 예측치들을 제공하고 있는 반면에 NBI 모형은 실제 판매량보다 훨 씬 높은 수준의 예측치들을 제공하고 있다. 따라서 반도체 시장의 역사상 가장 낮았던 성장 율을 기록한 1985 년의 $-16.5 \%$ 의 성장율울 참고(중앙일보, 2001 년 6월 23일)해 보면, 예측 성 과에 있어서 NB1 모형이 JP2 모형보다 열등하게 나타난 결과는<그림 1>에서처럼 1985년 1 분기와 2분기에 있어서 기대하지 못했던 판매량의 양상에서 볼 수 있듯이 돌연한 반도체 시 장의 불황에 기인한 것 같다.

<표 1> 전세계 DRAM 출하량 자료(74/1Q-84/4Q)에 대한 NB1 모형의 추정결과

\begin{tabular}{cccc}
\hline Parameter & Est imate & $\begin{array}{c}\text { Approximate } \\
\text { Standard Error }\end{array}$ & $\begin{array}{c}\text { Approximate } \\
\text { Prob }>|\mathrm{t}|\end{array}$ \\
\hline$p$ & 0.000165 & 0.000013 & 0.0001 \\
$q_{1}$ & 0.678456 & 0.0195 & 0.0001 \\
$q_{2}$ & 0.500419 & 0.00975 & 0.0001 \\
$q_{3}$ & 0.331028 & 0.00753 & 0.0001 \\
$q_{4}$ & 0.481721 & 0.0262 & 0.0001 \\
$m_{1}$ & 19860.96 & 557.6 & 0.0001 \\
$m_{2}$ & 60204.85 & 2282.7 & 0.0001 \\
$m_{3}$ & 389500.6 & 22126.1 & 0.0001 \\
$m_{4}$ & 423230.8 & 116982 & 0.0008 \\
\hline
\end{tabular}

<표 2> 전세계 DRAM 출하량 자료(74/1Q-84/4Q)에 대한 JP1 모형의 추정결과

\begin{tabular}{cccc}
\hline Parameter & Est imate & $\begin{array}{c}\text { Approximate } \\
\text { Standard Error }\end{array}$ & $\begin{array}{c}\text { Approximate } \\
\text { Prob> } \text { t | }\end{array}$ \\
\hline$c$ & 8.32677 & 0.2443 & 0.0001 \\
$q_{1}$ & 0.45063 & 0.0288 & 0.0001 \\
$q_{2}$ & 0.30547 & 0.0108 & 0.0001 \\
$q_{3}$ & 0.332593 & 0.0135 & 0.0001 \\
$q_{4}$ & 0.460737 & 0.0388 & 0.0001 \\
$M_{1}$ & 120145.5 & 49674.1 & 0.0201 \\
$M_{2}$ & 24632.53 & 1237.4 & 0.0001 \\
$M_{3}$ & 118582.5 & 12682.0 & 0.0001 \\
$M_{4}$ & 367213.8 & 9307.9 & 0.0001 \\
\hline
\end{tabular}


<표 3> 전세계 DRAM 출하량 자료(74/1Q-84/4Q)에 대한 JP2 모형의 추정졀과

\begin{tabular}{cccc}
\hline Parameter & Est imate & $\begin{array}{c}\text { Approximate } \\
\text { Standard Error }\end{array}$ & $\begin{array}{c}\text { Approximate } \\
\text { Prob> | t | }\end{array}$ \\
\hline$c$ & 9.499186 & 0.2284 & 0.0001 \\
$q_{1}$ & 0.08801 & 0.0101 & 0.0001 \\
$q_{2}$ & 0.203744 & 0.0107 & 0.0001 \\
$q_{3}$ & 0.341766 & 0.0154 & 0.0001 \\
$q_{4}$ & 0.604707 & 0.0440 & 0.0001 \\
$N_{1}$ & 16542889 & 15886286 & 0.3038 \\
$N_{2}$ & 30580461 & 7902183 & 0.0004 \\
$N_{3}$ & 6787958 & 693080 & 0.0001 \\
$N_{4}$ & 3811218 & 187763 & 0.0001 \\
\hline
\end{tabular}

<표 4> DRAM 자료를 이용하여 NB1, JP1, JP2 모형들간의 적합도와 예측능력 비교

\begin{tabular}{c|cccc}
\hline & NB1 & $\mathrm{JP1}$ & $\mathrm{JP2}$ & $\begin{array}{c}\text { 실제 판매량 } \\
\text { (256k) }\end{array}$ \\
\hline $\begin{array}{l}\text { 적합 영역(74/1Q-84/4Q)에서의 } \\
\text { SSE(sum of squares error) }\end{array}$ & $2.3126 \mathrm{E} 9$ & $1.3853 \mathrm{E} 9$ & $22.1386 \mathrm{E} 9$ & - \\
\hline 예측 판매량(256k) 1985년도 1분기 & 29638 & 24183 & 18767 & 22720 \\
1985년도 2분기 & 49046 & 32535 & 19990 & 34695 \\
MAD(mean absolute deviations) & 10635 & 1812 & 9329 & - \\
\hline
\end{tabular}


단위: 천개

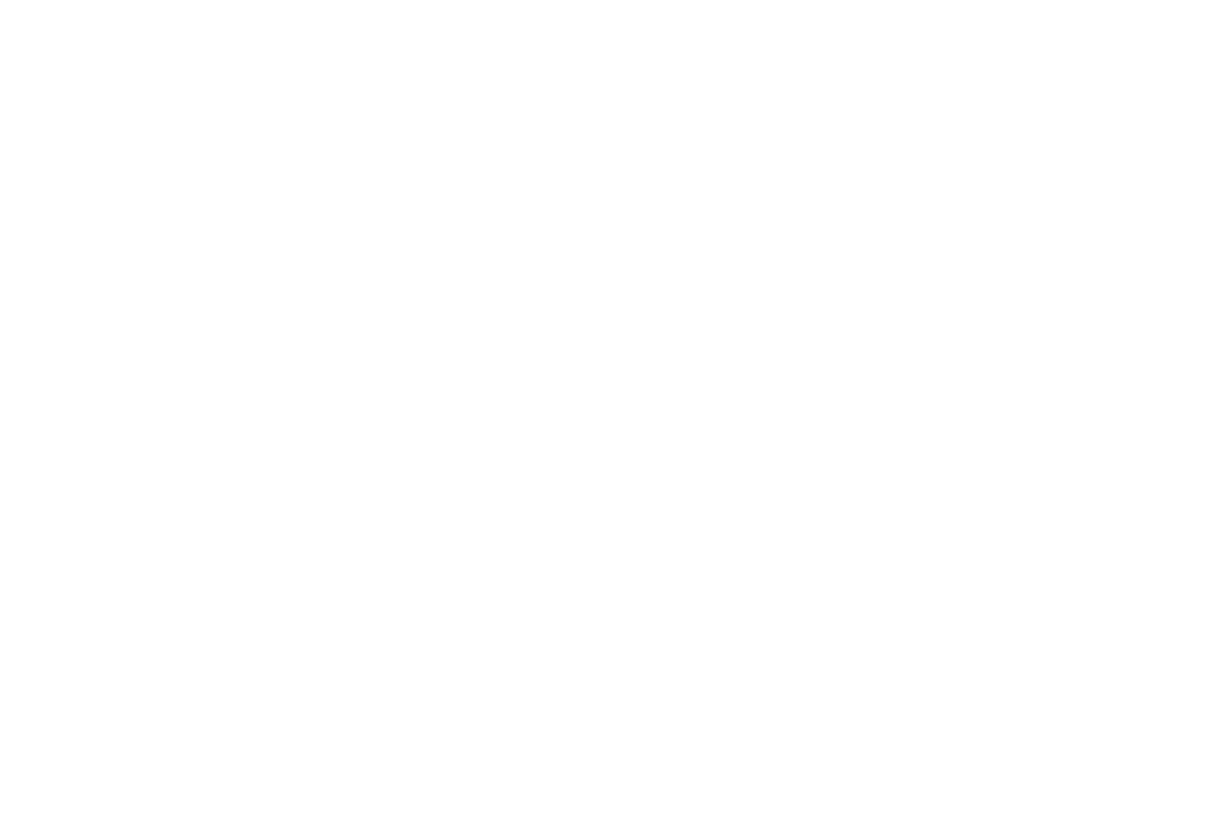

<그립 4> 전 세계 DRAN 출하량(74/1Q-84/4Q) : 간찰치와 JP1 모형의 적합치

단위: 천개

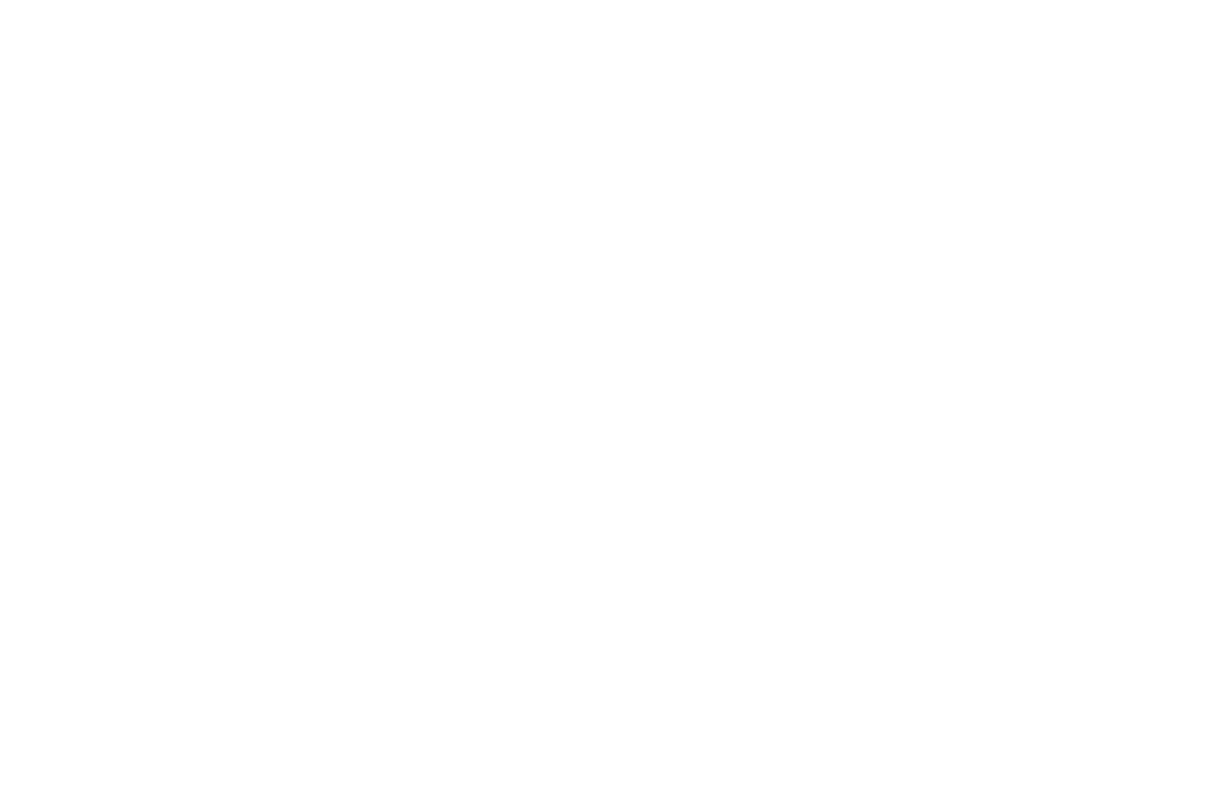




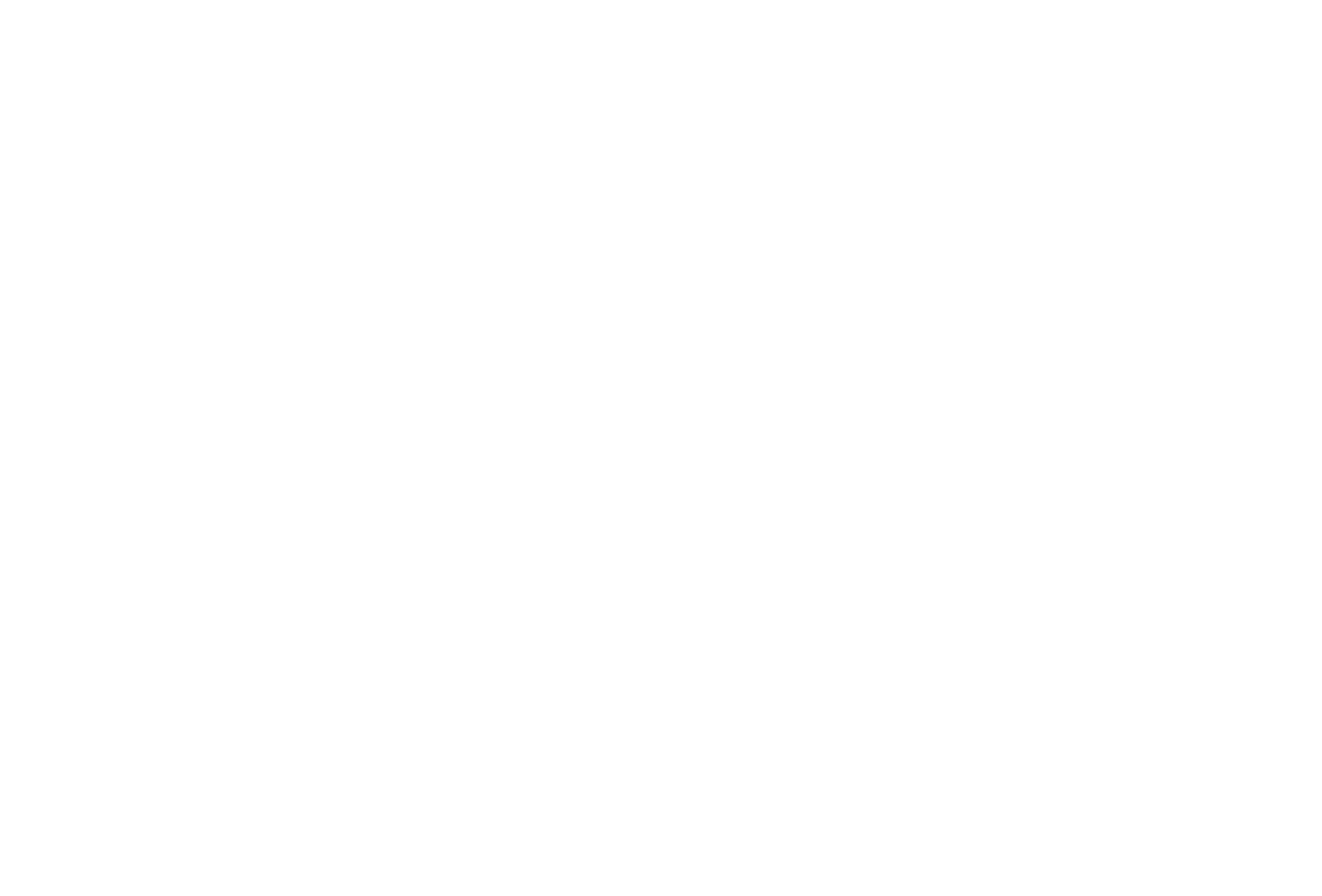

\section{4. 요약 및 토론}

첨단기술 제품들에서는 지속적인 기술혁신으로 신규세대와 이전세대들간의 대체시기가 점 점 짬아지고 있다. 그러므로 신규세대 제품의 수요와 신규세대 제품의 시장도입이 이전세대 제품들의 수요에 미치는 영향을 이해하는 것은 마케터에게 있어서 매우 중요한 작업이 되었 다. 가령 DRAM 반도체는 우리나라 전체 수출액에서 차지하는 비중이 단일 품목으로는 가 장 높은 제품인데, 잘못된 세대별 DRAM 반도체 수요분석으로 인한 투자결정은 한 개별회 사에 수 조원 이상의 손실을 끼칠 뿐만 아니라 우리나라 경제전체에도 심각한 영향을 미치 게 된다. 본 연구는 DRAM 반도체와 같은 다세대 내구성 기술제품에서 볼 수 있는 대체과 정(substitution process)과 확산과정(diffusion process)의 결과로 나타나는 신규세대 제품과 이전 세대 제품들의 동태적 판매량을 묘사하고 그 수요를 예측할 수 있는 모형들을 비교·분석하 였다.

본 논문에서 비교대상으로 삼은 다세대 확산모형들(multigeneration diffusion models)은 이 분 야에서 대표적인 모형인 Norton and Bass(1987), Mahajan and Muller(1996)와 Jun and Park(1999)이 개발한 모형들이다. Jun and Park(1999)은 다세대 제품들의 동태적 판매량 자료를 최초구매 수 요와 업그레이드 수요를 구분할 수 있는 자료(타입 I)와 없는 자료(타입 II)로 분류하고서, 타입 I 자료와 타입 II 자료에 각각 적용할 수 있는 타입 I 모형과 타입 II 모형을 개발하였 다. Jun and Park은 그들의 타입 1 모형을 포합하여 Norton and Bass의 모형과 Mahajan and 
Muller의 모형 둥은 타입 I 자료에만 적용할 수 있고 전세계 DRAM 반도체 출하량 자료와 같은 타입 II 자료에는 적용할 수 없다고 주장하면서, 전세계 DRAM 반도체 출하량 자료에 적용할 수 있는 새로운 모형으로서 타입 II 모형율 제시하였다. 그러나 본 연구에서는 각 모 형의 이론적인 틀과 가정들을 비교.검토함으로써 Jun and Park의 타입 I 모형은 소비자들의 선택행동의 결과인 선택확률을 고려하여 Mahajan and Muller의 모형올 확장한 형태임을 보여 주었고, 원래의 타입 I 모형의 가정들을 변화시킴으로써 모형을 구성하는 변수와 계수들의 의미가 변화된 모형(즉 JP1)을 제시하였다.

또한 전세계 DRAM 반도체 출하량 자료를 사용하여 Norton and Bass의 모형(NB1), Jun and Park의 타입 I 모형에서 최종 사용자들이 아닌 웅용기기들을 DRAM 반도체의 수용자들로 간주하고 응용기기들은 한 단위가 아닌 여러 단위들욜 반복구매한다고 가정하여서 그 의미 를 변화시킨 모형(즉 JP1)과 Jun and Park이 원래 이 자료에 적용한 타입 II 모형(즉 JP2)의 경헙적비교를 행하였는데, 그 결과는 다음과 같다.

첫째, 적합영역(즉 1974년 1분기부터 1984년 4분기까지)의 DRAM 반도체 출하량 자료를 사 용하여 구해낸 각 모형의 모수 추정치들의 액면타당성(parameter face validity)에 있어서는 NB1 모형, JP1 모형, JP2 모형이 모두 전반적으로 우수하였고, 모형간의 뚜렷한 우열을 나누 어 볼 수 없었다. 둘째, 모형의 적합 능력(fitting ability)에 있어서는 JP1 모형이 NB1모형보다 약간 우수하였고, JP2 모형은 JP1 모형과 NB1 모형에 비해서 힐씬 열등한 적합결과를 보여 주었다. 셋째, 모형의 예측성과(predictive performance)에 있어서 JP1 모형이 가장 우수하였고, 그 다음으로 JP2 모형이 NB1 모형보다 약간 우수하게 나타넜다. 그러나 JP2 모형과 NB1 모 형의 분기별 예측 판매량과 실제 판매량을 비교한 결과와 반도체 시장의 역사상 가장 낮았 던 성장율을 기록한 1985 년의 $-16.5 \%$ 의 성장율을 고려해 보면, 예측 성과에 있어서 NB1 모형이 JP2 모형보다 열둥하게 나타난 결과는 1985년의 돌연한 반도체 시장의 불황에 기인 한 것 같다. 결론적으로 각 모형이 제공하는 모수 추정치들의 액면타당성, 모형의 적합능력 과 예측타당성을 전반적으로 고려해 볼 때 JPI 모형이 가장 우수하게 나타났고, 그 다음으 로 NB1 모형과 JP2 모형의 순서로 나타났다.

Jun and Park(1999)이 전세계 DRAM 반도체 출하량 자료에 적용하기 위하여 새롭게 개발한 타입 II 모형(즉 JP2)은 그들의 연구결과와 같이 Bass(1969)의 최초구매 확산모형보다는 우월 할 수 있겠지만, 본 연구의 경험적 비교의 결과에 비추어 볼 때 그들의 타입 1 모형이 취한 가정들을 변화시켜서 모형을 구성하는 변수들과 계수들의 의미가 달라진 JP1 모형 또는 Norton and Bass(1987)의 모형(즉 NB1)보다 실제 적용에 있어서 열등할 수 있다는 것올 본 연 구는 보여준다. 그러나 이것은 4개 세대들로 구성된 DRAM 반도체 출하량 자료를 사용하여 도출한 잠정적 결론이고, 이룔 일반적인 결과로 받아들이기 위해서는 보다 다양한 다세대 내구성 기술제품들에 대한 모형간 경협적 비교가 시도되어야 할 것이다.

본 연구에서는 1974년부터 1985년 2분기까지 분기별 전세계 DRAM 출하량 자료를 분석 대상으로 4 개 세대(즉 $4 \mathrm{~K}, 16 \mathrm{~K}, 64 \mathrm{~K}, 256 \mathrm{~K}$ )의 세대간 확산 및 대체과정을 반영한 다세대 확 산모형들(즉 NB1, JP1, JP2)을 예시하였다. 그러나 그 이후에 DRAM 반도체는 $1 \mathrm{M}, 4 \mathrm{M}, 16 \mathrm{M}$, $64 \mathrm{M}, 128 \mathrm{M}, 256 \mathrm{M}$ 둥 새로운 세대들이 시장에 진입하여 확산 및 대체과정을 보여주었다. 본 논문에서 분석한 4개세대보다 더 많은 세대간의 확산 및 대체과정을 분석하기 위해서 NB1 모형은 4 세대 분석을 위한 식돌(즉 식(2.12)부터 식 (2.15)까지)에서 볼 수 있는 반복적인 특 징을 활용하여 쉅게 더 많은 세대들을 분석할 수 있는 식들을 도출할 수 있다. JP1 모형 또 한 4세대들에 걸친 수용자들의 동태적 흐름(즉<그립 2>)에서 볼 수 있는 반복적인 특징을 
고려하여 4세대 분석을 위한 식들(즉 식(2.30)부터 식(2.39)까지)로 부터 더 많은 세대들을 분 석할 수 있는 식들을 읩게 반복적으로 도출할 수 있고, JP2 모형(즉 식(2.40))은 모형의 구조 상 뉩게 더 많은 세대들로 확장할 수 있다. 그러므로 가능한한 최근까지의 DRAM 출하량 자료를 구하여 모형간 경험적 비교를 시도하여서 본 연구에서 제시한 모형간 비교결과률 뒷 받침할 수 있는 장래의 연구를 행할 펼요가 있다.

마지막으로 본 연구에서는 다세대 확산모형들 간에 모형 구조상의 우월성 비교에 초점을 맞추었기 때문에 마케팅믹스 변수들올 포함하지 않았지만, 마케팅 관리적 관점에서는 마케 팅믹스 변수들(가령 가격변수)을 포함한 모형들에 대한 연구가 시도되어야 할 것이다. 가령 NB1 모형에 가격변수를 포함한 Speece and MacLachlan(1995)의 연구 둥을 참고하여 새로운 모형의 제시와 모형간의 우월성 비교를 시도할 수 있을 것이다. 


\section{<참고문헌>}

Bass, F. M. (1969), “A New Product Growth Model for Consumer Durables," Management Science, 15(January), pp. 215-227.

Bass, F. M. , T. V. Krishnan, and D. C. Jain(1994), "Why the Bass Model Fits without Decision Variables," Marketing Science, 13(Summer), pp. 203-223.

Ben-Akiva, M. and S. R. Lerman(1985), Discrete Choice Analysis: Theory and Applications to Travel Demand, MIT Press, Cambridge, MA.

Jun D. B. and Y. S. Park(1999), “A Choice-Based Diffusion Model for Multiple Generations of Products," Technological Forecasting and social Change, 61, pp. 45-58.

Mahajan, V., C. H. Mason, and V. Srinivasan(1986), "An Evaluation of Estimation Procedures for New Product Diffusion Models, " in Innovation Diffusion Models of New Product Acceptance, V. Mahajan and Y. Wind, eds. Cambridge, MA.: Ballinger Publishing Company.

_ , and E. Muller(1996), "Timing, Diffusion, and Substitution of Successive Generations of Technological Innovations: The IBM Mainframe Case," Technological Forecasting and Social Change, 51, pp. 109-132.

_, , and F. M. Bass(1990). "New Product Diffusion Models in Marketing: A Review and Directions for Research," Journal of Marketing, 54, pp. 1-26.

Norton, J. A. and F. M. Bass(1987),"A Diffusion Theory Model of Adoption and Substitution for Successive Generations of High-Technology Products, "Management Science, 33(9), pp. 1069-1086.

_ and _ (1992), Evolution of Technological Generations: The Law of Capture," Sloan Management Review, 33, pp. 66-77.

Rogers, E. M.(1983), The Diffusion of Innovation, Third Ed., Free Press, New York.

SAS Institute(1993), SAS/ETS User's Guide, Version 6 Edition, SAS Institute, Cary, N.C.

Schmittlein, D. C. and V. Mahajan(1982), "Maximum Likelihood Estimation for an Innovation Diffusion Model of New Product Acceptance, “ Marketing Science, 1(Winter), pp. 57-78.

Speece, M. W. and D. L. MacLachlan(1995), “Application of a multi-generation Diffusion Model to Milk Container Technology, "Technological Forecasting and Social Change, 49(July), pp. 281-295.

Srinivasan, V. and C. H. Mason (1986), "Nonlinear Least Squares Estimation of New Product Diffusion Models," Marketing Science, 5(Spring), pp. 169-178.

Sultan, F., J. U. Farley, and D. R. Lehmann(1990), "A Meta-Analysis of Applications of Diffusion Models," Journal of Marketing Research, 27(February), pp. 70-77 